ARTICLE

DOI: $10.1038 / s 41467-018-04926-x$

\title{
Antifungal tolerance is a subpopulation effect distinct from resistance and is associated with persistent candidemia
}

Alexander Rosenberg${ }^{1}$, luliana V. Ene ${ }^{2}$, Maayan Bibi ${ }^{1}$, Shiri Zakin ${ }^{1}$, Ella Shtifman Segal ${ }^{1}$, Naomi Ziv $^{3}$, Alon M. Dahan ${ }^{1}$, Arnaldo Lopes Colombo ${ }^{4}$, Richard J. Bennett ${ }^{2} \&$ Judith Berman (1) ${ }^{1}$

Tolerance to antifungal drug concentrations above the minimal inhibitory concentration (MIC) is rarely quantified, and current clinical recommendations suggest it should be ignored. Here, we quantify antifungal tolerance in Candida albicans isolates as the fraction of growth above the MIC, and find that it is distinct from susceptibility/resistance. Instead, tolerance is due to the slow growth of subpopulations of cells that overcome drug stress more efficiently than the rest of the population, and correlates inversely with intracellular drug accumulation. Many adjuvant drugs used in combination with fluconazole, a widely used fungistatic drug, reduce tolerance without affecting resistance. Accordingly, in an invertebrate infection model, adjuvant combination therapy is more effective than fluconazole in treating infections with highly tolerant isolates and does not affect infections with low tolerance isolates. Furthermore, isolates recovered from immunocompetent patients with persistent candidemia display higher tolerance than isolates readily cleared by fluconazole. Thus, tolerance correlates with, and may help predict, patient responses to fluconazole therapy.

\footnotetext{
${ }^{1}$ School of Molecular Cell Biology and Biotechnology, Tel Aviv University, 6997801 Ramat Aviv, Israel. ${ }^{2}$ Department of Molecular Microbiology and Immunology, Brown University, Providence, RI 02912, USA. ${ }^{3}$ Department of Microbiology and Immunology, University of California, San Francisco, CA 94143, USA. ${ }^{4}$ Department of Medicine, Federal University of São Paulo, São Paulo 04021-001, Brazil. These authors contributed equally: Alexander Rosenberg, Iuliana V. Ene. Correspondence and requests for materials should be addressed to J.B. (email: judithberman11@gmail.com)
} 
goal of antimicrobial susceptibility testing is to predict the clinical success or failure of antibiotic therapy. Some infections are recalcitrant to drug treatment due to "resistance", which refers to microbial growth in the presence of drug concentrations that inhibit susceptible isolates ${ }^{1}$. Susceptibility is commonly measured as the minimal inhibitory concentration (MIC) after $24 \mathrm{~h}$ of growth in the presence of $\operatorname{drug}^{2}$. Fungal infections generally follow the "90/60" rule for predicting therapeutic outcomes based on in vitro susceptibility testing: $~ 90 \%$ of susceptible isolates and $\sim 60 \%$ of resistant isolates respond to therapy ${ }^{3,4}$. This implies that infection outcomes are influenced by host factors as well as features of the pathogen that are not reflected by the $\mathrm{MIC}^{5,6}$. In effect, organisms that cause persistent infections, defined as those that are not cleared by a course of antifungal treatment, have similar susceptibilities to organisms that are readily cleared by a course of antifungal treatment $^{7}$. Accordingly, it is important to identify measurable parameters that can contribute to disease severity.

Only four classes of antifungals are currently in clinical use, and resistance to azoles, including fluconazole (FLC), the most commonly administered antifungal against Candida species, is an increasing problem. Altered drug uptake or efflux and changes in ergosterol biosynthesis (the target for azole drugs) ${ }^{8}$ are the major known mechanisms of azole resistance. Stress responses have been proposed as a third mechanism of antifungal resistance ${ }^{9}$. A broad range of small molecules enhance antifungal activity in vitro and in vivo, with inhibitors of Hsp90, calcineurin, and TOR the most prominent among them ${ }^{10,11}$. Combination therapy using antifungals together with such inhibitors has been proposed as a promising strategy to extend the efficacy of current drugs $^{12,13}$. In addition, several psychotherapeutic agents such as fluoxetine, fluphenazine (FNZ), or sertraline can enhance FLC activity against fungal species ${ }^{14,15}$. Whether such adjuvants affect therapeutic outcomes remains to be addressed.

Persistent candidemia, defined as the failure to clear a bloodstream infection caused by a susceptible organism ${ }^{7,16}$, is associated with increased mortality. In one study, the mortality rate was $54 \%$ among infections with persistent candidemia and only $3 \%$ among those with non-persistent (NP) candidemia ${ }^{17}$. Mechanisms underlying persistent candidemia may include variability in the pharmacology of the drug, suboptimal dosing, presence of fungal biofilms on indwelling catheters, and reduced immunity. We posit that some responses to the drug are not captured by measuring the MIC alone and that additional parameters could be used to predict the likelihood that a clinical isolate might respond poorly to antifungal drugs. Furthermore, understanding the mechanisms that underlie these parameters is critical for the development of new therapeutic approaches against persistent Candida infections.

MIC measurements have been optimized to minimize or ignore residual fungal growth ${ }^{4,18}$, termed "tolerance" or "trailing growth", which has been discussed in the literature for over 20 years and is detected in $25-60 \%$ of clinical isolates ${ }^{2,5,19}$. This recommendation is based upon studies of acute infections using the mouse model of bloodstream candidiasis ${ }^{20}$, and the observation that isolates with high trailing growth in mucosal infections respond positively to short-term antifungal treatment, despite later recurrence of infection ${ }^{21}$. Trailing growth is sensitive to environmental conditions, including $\mathrm{pH}$, temperature, and nutrients ${ }^{22-24}$ and is usually detected in liquid cultures. Definitions of "tolerance" vary and generally describe survival or growth above inhibitory concentrations $s^{1,5,14,19}$, detected as slow growth within the zone of inhibition using E-strips or disk diffusion assays $^{25}$, or in broth microdilution assays ${ }^{19}$. Tolerance can be affected by several adjuvant drugs ${ }^{12}$, iron levels ${ }^{26}$, and genes involved in vacuolar protein sorting ${ }^{19}$, as well as calcium flux ${ }^{14,27,28}$. However, the precise relationship between the outcome of fungal infections and tolerance or trailing growth has not been determined. Because tolerant cells continue to divide in the presence of antifungals, we postulated that they contribute to the persistence and/or recurrence of fungal infections.

Here, we measure susceptibility and tolerance in a broad range of clinical isolates spanning the major Candida albicans clades $^{29,30}$ and ask how these parameters influence fungal infection outcomes. We analyze disk diffusion assays using diskImage R, and quantify the radius (RAD) of the zone of inhibition, a parameter that relates to the $\mathrm{MIC}^{31}$, and the fraction of growth (FoG) within the zone of inhibition, a parameter that measures tolerance ${ }^{19,24,26,32}$. We found that a range of adjuvant drugs, used in combination with FLC, increased drug cidality by reducing FoG and not MIC and are effective both in vitro and in vivo at inhibiting strains with high (and not low) FoG levels. Finally, highly tolerant isolates are associated with persistent candidemia, suggesting that knowing the tolerance level of an infecting isolate may have important clinical implications and may inform treatment options.

\section{Results}

Tolerance measured as FoG is distinct from drug resistance. We quantified drug responses in C. albicans isolates from different genetic backgrounds and types of infections using diskImageR, a quantitative analysis tool that measures RAD of the zone of inhibition, an indicator of susceptibility that relates to MIC, and FoG within the zone of inhibition, relative to the maximum possible growth ${ }^{31}$ (Fig. 1a). A screen of 219 clinical isolates (Supplementary Data 1) revealed that FoG levels ranged widely from 0.10 to 0.85 and did not correlate with RAD levels (Fig. 1b, c), indicating that FoG and RAD measure independent drug responses. FoG was detected in response to other drugs including fungistatic antifungals (azoles, 5-fluorocytosine) and, to a lesser degree, to fungicidal agents (echinocandins, polyenes) (Supplementary Fig. 1a). Antifungal responses varied widely in different Candida species as well as in Saccharomyces cerevisiae (Supplementary Fig. 1b). For example, Candida glabrata exhibited the highest tolerance to azoles, followed by Candida tropicalis and Candida krusei, while S. cerevisiae had low tolerance to azoles and intermediate tolerance to echinocandins and polyenes.

Broth microdilution assays define the $\mathrm{MIC}_{50}$-the lowest drug concentration that inhibits $50 \%$ of growth at $24 \mathrm{~h}$ (termed MIC throughout the manuscript). Most reports of "trailing growth" or "tolerance" monitor growth at $48 \mathrm{~h}^{23,24,33}$. We quantified supraMIC growth (SMG) at $48 \mathrm{~h}$ (average growth per well above the $\mathrm{MIC}_{50}$, normalized to growth without FLC; Fig. 1d). Most isolates exhibited some level of SMG at $48 \mathrm{~h}$, while MIC levels remained unchanged between 24 and $48 \mathrm{~h}$ (Fig. 1e-g). Thus, SMG provides a parameter that, like FoG, is distinct from MIC.

Importantly, cells exhibiting FoG in disk assays or SMG in broth assays are not due to the emergence of drug resistance. Thus, for a given isolate, FoG and SMG levels were reproducible for cells taken from inside or outside the zone of inhibition, or for cells taken from wells above or below the MIC (Supplementary Fig. 2a, b). These cells yield progeny indistinguishable from other cells in the population, and thus are the result of phenotypic heterogeneity rather than genetic alteration. Consequently, tolerance is due to growth heterogeneity in the population and is stable for a given isolate.

While SMG and FoG correlated well with each other $\left(R^{2}=\right.$ $0.82, P<0.01)$, there was no relationship between FoG and RAD $\left(R^{2}<0.01\right)$, or SMG and MIC $\left(R^{2}=0.25, P<0.01\right.$, Supplementary Fig. 2c). FoG and SMG therefore reflect similar features of growth at supra-MIC concentrations that are distinct from drug 
a

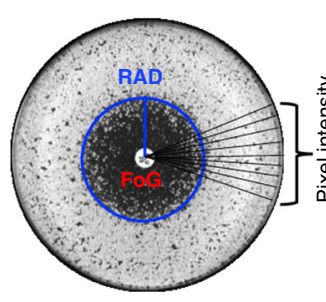

d

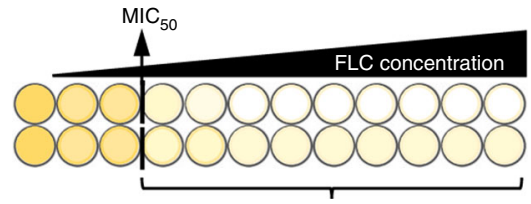

$\mathrm{SMG}=$

Average $48 \mathrm{~h}$ growth above $\mathrm{MIC}_{50}$

Growth without FLC b

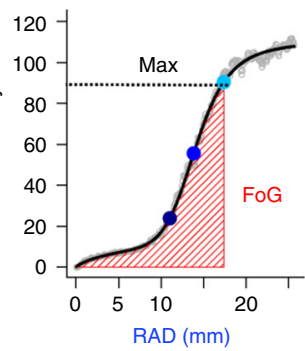

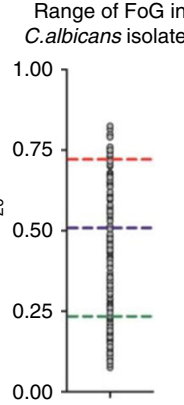

C

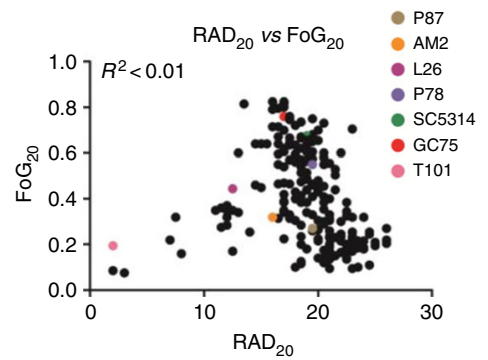

e

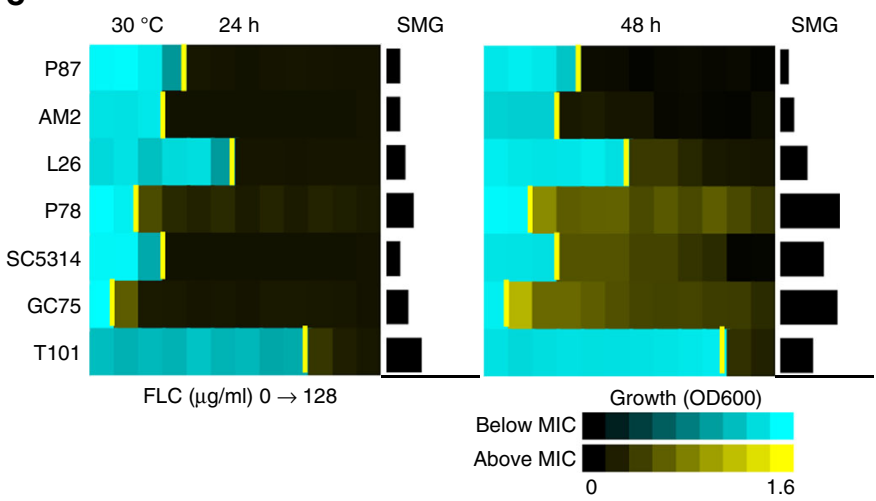

f

g
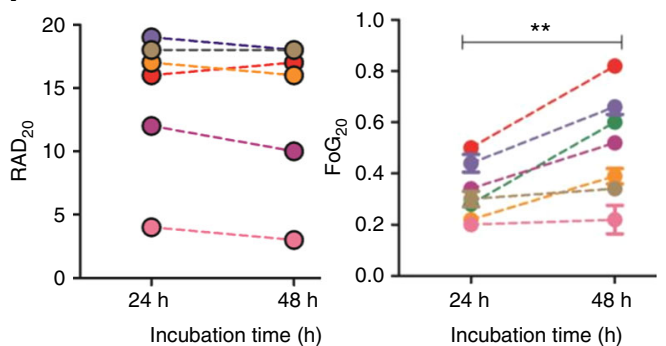

h

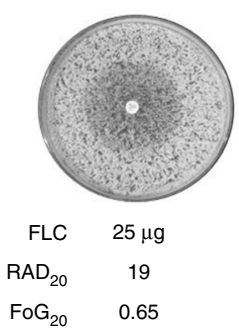

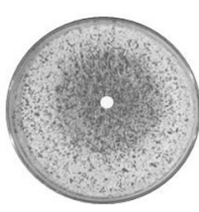

$50 \mu \mathrm{g}$

21

0.64

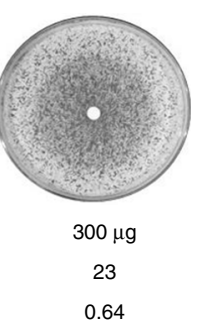

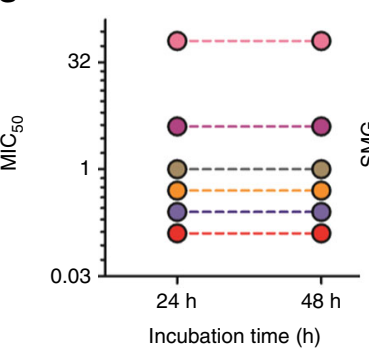
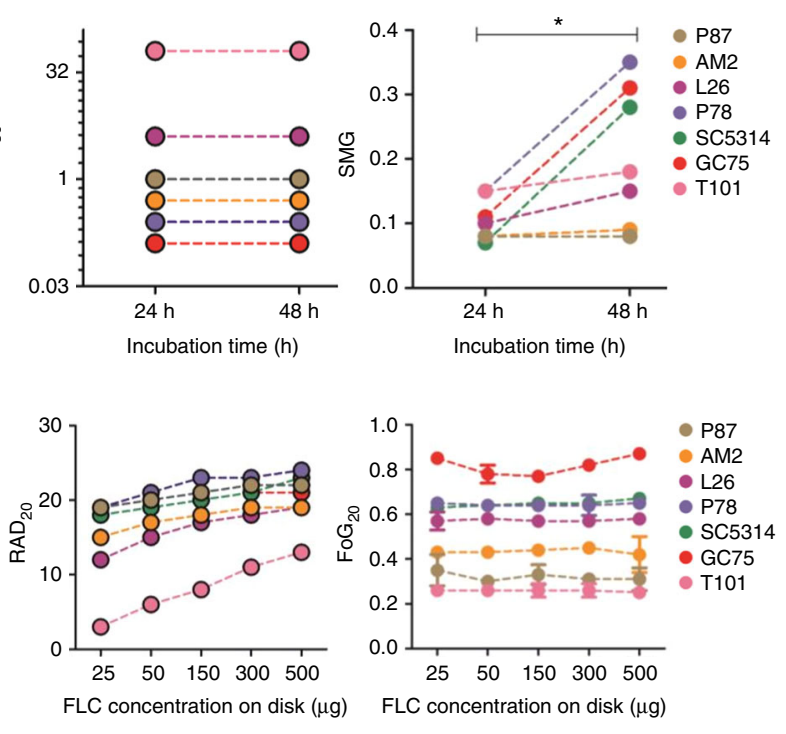

Fig. 1 Measuring drug responses in disk diffusion assays (DDAs) and in liquid broth microdilution assays (BMDAs). a disklmage $R$ analysis measures pixel intensity corresponding to cell density, along 72 radii every $5^{\circ}$. The average radius (RAD) represents the distance in mm corresponding to the point where $20 \%, 50 \%$, or $80 \%$ growth reduction occurs (light, medium, dark blue dots). The fraction of growth inside the zone of inhibition (FoG) is the area under the curve (red) at the RAD threshold, divided by the maximum area. b Range of FoG levels in 219 C. albicans clinical isolates. Red, blue, and green lines estimate high, medium, and low FoG levels, respectively. Unless otherwise specified, DDAs were performed using a single $25 \mu \mathrm{FLC}$ disk and analyzed after $48 \mathrm{~h}$ at $30^{\circ} \mathrm{C}$. c Comparison of $\mathrm{FoG}_{20}$ and $\mathrm{RAD}_{20}$ for the 219 isolates. d Illustration of MIC and supra-MIC growth (SMG) calculations. MIC 50 was calculated at $24 \mathrm{~h}$ as the FLC concentration at which $50 \%$ of the growth was inhibited, relative to growth in the absence of drug. SMG was calculated as the average growth per well above the MIC divided by the level of growth without drug. FLC was used in two-fold dilutions $(0,0.125$ to $128 \mu \mathrm{g} / \mathrm{ml})$. e Heatmaps illustrating $\mathrm{OD}_{600}$ levels for concentrations below the MIC (yellow bar) in cyan and above the MIC in yellow for the isolates from Fig. 1c. Maps show $\mathrm{OD}_{600}$ values at 24 and $48 \mathrm{~h}$. f, $\mathbf{g}$ Effect of incubation time on RAD/MIC and FoG/SMG values. diskImageR analysis (f) and corresponding MIC and SMG levels $(\mathbf{g})$ measured at 24 and $48 \mathrm{~h}$ for strains as in $\mathbf{d}$. Of note, for truly drug-resistant strains such as T101 (MIC $=64$, e), the small zone of inhibition makes FoG measurements less accurate than SMG levels. $\mathbf{h}$ RAD is concentration-dependent and FoG is concentration-independent as illustrated for strain SC5314 exposed to disks containing increasing concentrations of FLC (25, 50 and $300 \mu g$ ) (left); RAD (middle) and FoG (right) levels for strains as listed. For all panels, $n \geq 2 ;{ }^{\star \star} P<0.01 ;{ }^{\star} P<0.05$ 
susceptibility/resistance, as measured by RAD or MIC, which are concentration-dependent parameters. Accordingly, whereas RAD increased with increasing drug concentrations in the disk (Fig. 1h), FoG remained similar irrespective of drug concentration. Similarly, SMG levels remained constant across a broad range of supra-MIC concentrations (Fig. 1e). Thus, tolerance measured as FoG or SMG is not dependent upon drug concentration, highlighting the distinctive nature of tolerance relative to susceptibility/resistance.

Environmental modulation of drug responses. FoG and SMG levels were reduced at $\mathrm{pH} 4.5$ relative to $\mathrm{pH} 7$, while $\mathrm{RAD} / \mathrm{MIC}$ levels remained relatively stable (Supplementary Fig. 3a, b). FoG/ SMG values also decreased with higher temperatures $\left(37-41^{\circ} \mathrm{C}\right)$, while $\mathrm{RAD} / \mathrm{MIC}$ levels showed less variation with increasing temperature (Supplementary Fig. 3c, d). For some strains, including SC5314, RAD and/or FoG levels varied considerably depending on the growth media (Supplementary Fig. 3e). A series of strains derived from SC5314 by passaging were particularly sensitive to media differences, with lower RAD and higher FoG levels on rich medium (YPD) than on casitone medium (Supplementary Fig. 3f), emphasizing that assays must be performed under consistent conditions to ensure reproducible results. Importantly, differences in genetic background can have a major effect on how $C$. albicans strains respond to environmental conditions.

Subpopulation growth dynamics. To ask if tolerance reflects the size of a dividing subpopulation at supra-MIC concentrations, we compared the number of cells that form colonies (colony-forming units (CFUs)) in the presence of supra-MIC FLC concentrations to total CFUs without drug. CFUs on drug ranged between $2 \%$ and $98 \%$ of the total population and correlated with FoG levels (Fig. 2a, $R^{2}=0.91, P<0.01$ ). The proportion of the subpopulation that grew at supra-MIC FLC in liquid cultures did not change with inoculum size (Supplementary Fig. 3g), indicating that FoG/SMG is independent of cell density. Importantly, these results establish that FoG levels represent the proportion of the population that can form colonies or grow above the MIC.

Growth dynamics were also monitored using microcolony assays, in which time-lapse microscopy follows colony area/size (Fig. 2b) ${ }^{34}$. As expected, exponentially growing cells plated on 10 $\mu \mathrm{g} / \mathrm{ml}$ FLC did not stop growing immediately. Rather, most cells continued dividing for $\sim 5 \mathrm{~h}$, and then slowed or stopped dividing to different degrees (Fig. 2c, d and Supplementary Movies 1-4). In high FoG isolates (e.g., SC5314), a large proportion of the cells yielded microcolonies, while in low FoG isolates (e.g., P87), more cells stopped dividing (black dots in Fig. 2b). Differences in growth rates became apparent after $10-15 \mathrm{~h}$ in FLC (Fig. 2d), supporting the idea that different subpopulations have different growth dynamics, and that high FoG strains produce a larger subpopulation of growing colonies than low FoG isolates.

The dynamics of colony growth on agar plates was also examined using ScanLag, a flatbed scanner/image analysis pipeline $^{35}$ that we adapted for use with $C$. albicans. Here, the area occupied by light pixels and the change in this area over time are proxies for colony size and growth rate, respectively ${ }^{35}$. Different $C$. albicans isolates exhibited different initial time of colony appearance (ToA) on medium without drug (Supplementary Fig. 4). At $10 \mu \mathrm{g} / \mathrm{ml} \mathrm{FLC,} \mathrm{the} \mathrm{ToA} \mathrm{was} \mathrm{delayed} \mathrm{relative} \mathrm{to} \mathrm{the}$ drug-free condition (except for resistant strains such as T101, Fig. 2e, f). Notably, the $\triangle$ ToA (ToA on FLC - ToA without FLC) of high FoG isolates was shorter than that of low FoG isolates (Fig. 2f), and correlated with overall FoG levels (Fig. 2g). This suggests that high FoG strains overcome the inhibitory pressures of the antifungal more efficiently than low FoG strains. Consistent with this, in liquid assays with drug, highly tolerant isolates also displayed shorter lag times than related isolates with low tolerance levels (Supplementary Fig. 5a).

A number of $C$. albicans growth parameters did not correlate with FoG levels. These include cell viability in the presence of drug (Fig. 2h, Supplementary Note 1 and Supplementary Table 1), consistent with FLC being fungistatic rather than fungicidal. Unlike tolerant bacteria, which display reduced growth rates and longer colony appearance times ${ }^{1,36}$, antifungal tolerance did not correlate with slower growth in three sets of related C. albicans strains grown in liquid without drug, including: (1) passaged derivatives of SC5314 with altered FoG levels, (2) a slow-growing clinical isolate (P37005) and faster growing derivatives ${ }^{37}$ and (3) a clb4 mutant ${ }^{38}$ with delayed cell cycle progression relative to control strains (Supplementary Fig. 5b). Furthermore, exponential and stationary phases yielded similar FoG levels (Supplementary Fig. 5c), unlike phenotypic drug resistance in bacteria ${ }^{39}$ Growth parameters (colony size and growth rate, liquid growth rate, and lag phase duration) also failed to show any correlation with FoG levels (Supplementary Fig. 5d, e). This implies that tolerance is not simply a reflection of faster growth in the presence or absence of drug. Rather, it reflects two aspects of $C$. albicans growth dynamics: a larger subpopulation able to form colonies at supra-MIC drug concentrations (Fig. 2a), and a faster relative recovery in response to fungistatic pressure.

Decreased intracellular drug levels underlie increased tolerance. A recently developed fluorescent azole probe, FLC-Cy $5^{40}$, provides a powerful tool to monitor intracellular drug levels and uptake rates using flow cytometry (Fig. 3a). The initial rate of FLC-Cy5 uptake per cell varied between strains and showed a weak inverse correlation with FoG levels $\left(R^{2}=0.64, P=0.12\right.$, Fig. 3b). By contrast, steady-state FLC-Cy5 levels at $24 \mathrm{~h}$ correlated inversely with FoG levels $\left(R^{2}=0.8, P<0.01\right.$, Fig. 3c). Cells were categorized as having low, mid, and high levels of FLC-Cy5 (at $24 \mathrm{~h}$ ). FoG levels inversely correlated with the proportion of cells that contained high FLC-Cy5 levels $\left(R^{2}=0.82, P=0.04\right)$ and positively correlated with the proportion of cells containing mid FLC-Cy5 levels $\left(R^{2}=0.81, P=0.05\right.$, Fig. $3 \mathrm{~d}$, e).

Based on the assumption that the steady-state drug levels are influenced by both drug efflux and uptake, we measured efflux of Rhodamine 6G (R6G), a dye removed primarily via the ABC class of transporters ${ }^{41}$. In general, the rate of R6G efflux was higher in the presence, than in the absence, of FLC, with SC5314 as the notable exception (Fig. $3 \mathrm{f}$ and Supplementary Fig. 6a). Yet, efflux rates did not correlate with FoG under any of the conditions tested (Supplementary Fig. 6b, $R^{2}<0.2$ ). Thus, the determinants of steady-state intracellular FLC levels are complex, and include uptake and efflux rates, as well as other factors (Fig. 3g).

Adjuvant FLC combinations clear tolerance and do not alter resistance. Combination therapies have the potential to extend the lifespan of the few available antifungal drug classes ${ }^{12}$. We tested a series of adjuvant drugs to determine their quantitative effect on fungal responses when used together with FLC. Most adjuvants significantly reduced FoG. This includes geldanamycin and radicicol, which inhibit heat shock protein 90 (Hsp90) activity $^{13,28}$; cyclosporine A and FK506, which inhibit calcineurin $^{42,43}$; and staurosporine, which inhibits protein kinase $\mathrm{C} 1$ ( $\mathrm{Pkc1}$ ) activity ${ }^{44}$. In addition, other adjuvants not directly connected to Hsp90 function also reduced FoG, including aureobasidin $\mathrm{A}$, which inhibits sphingolipid biosynthesis; ${ }^{45}$ rapamycin, an inhibitor of the mammalian target of rapamycin (mTOR) signaling pathway; ${ }^{46}$ tunicamycin, an inducer of the 
a

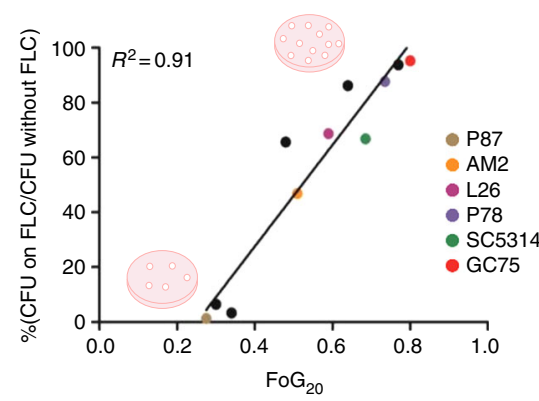

C

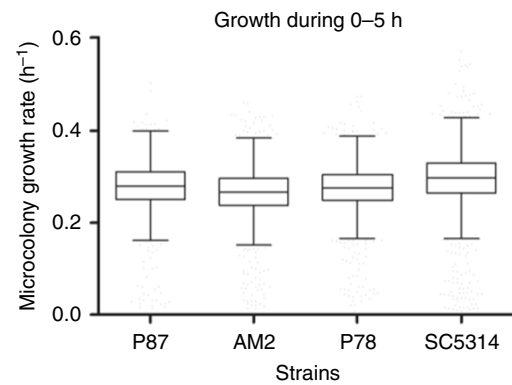

d

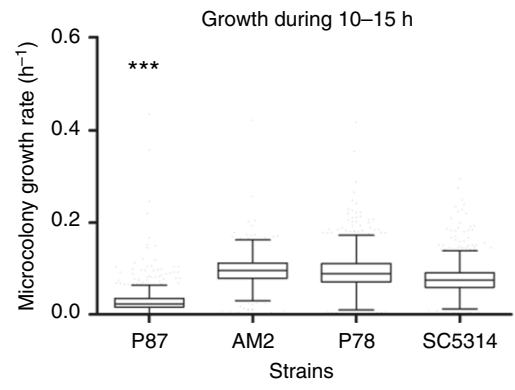

g

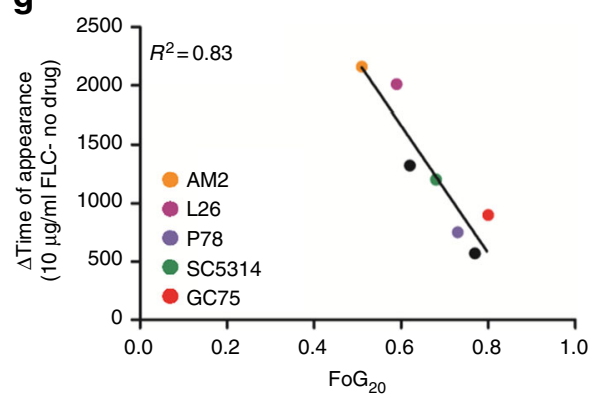

b
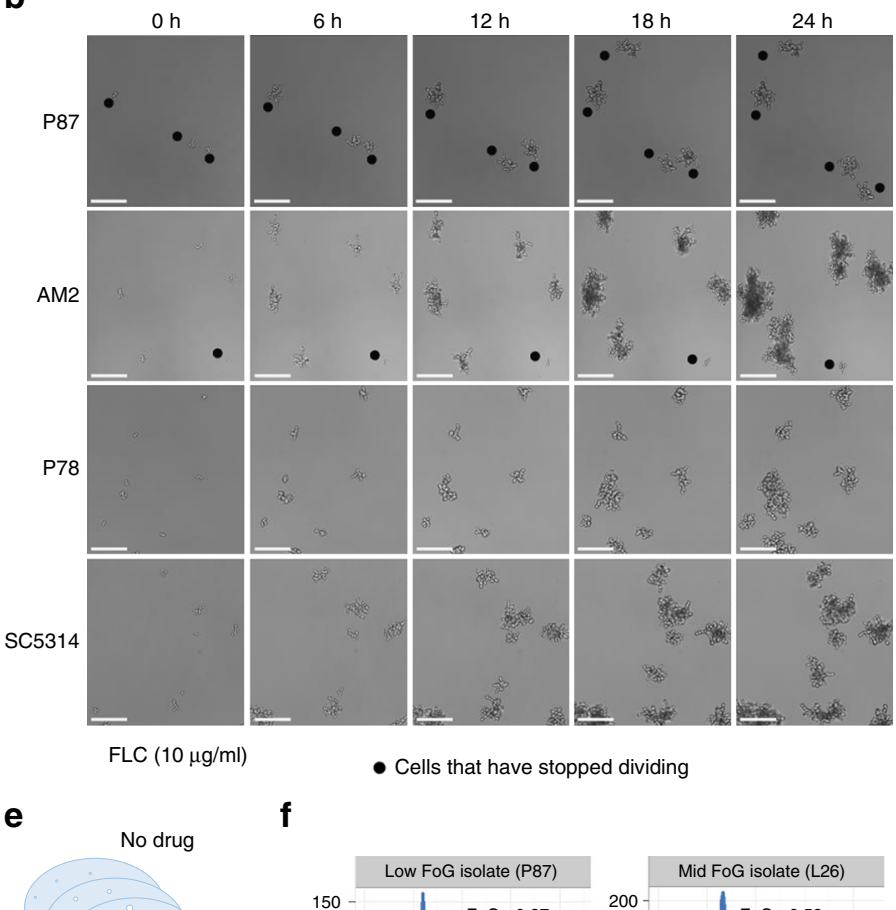

- Cells that have stopped dividing

\section{f}
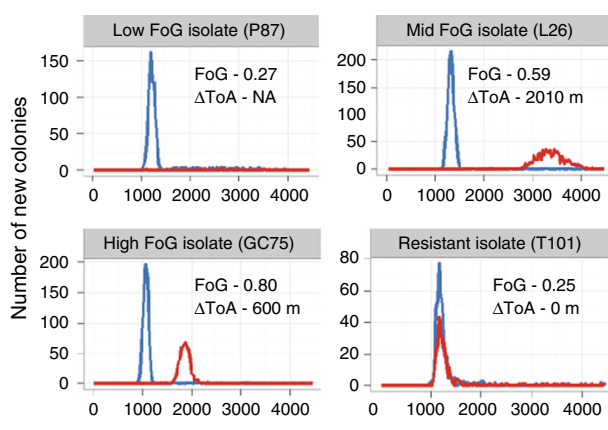

First time ( $\mathrm{min}$ ) of new colony appearance

$$
\text { — No drug }
$$

h

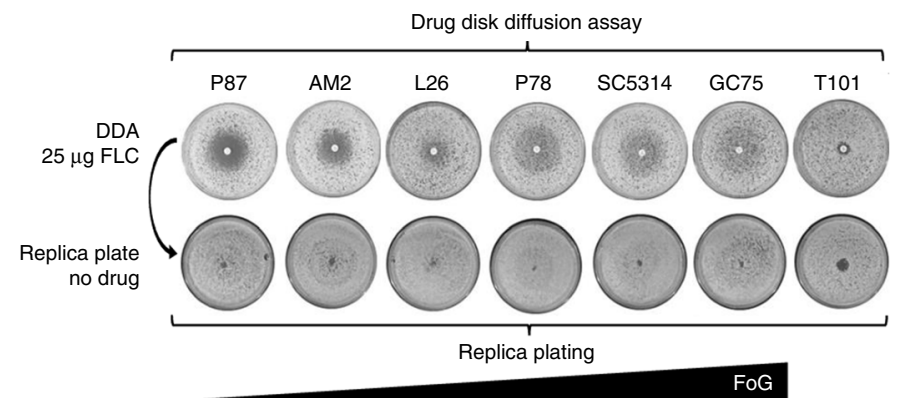

Fig. 2 Analysis of cells growing at supra-MIC concentrations. All tested strains, except for T101 (MIC =64 $\mu \mathrm{g} / \mathrm{ml})$, had FLC MIC values below $10 \mu \mathrm{gg} / \mathrm{ml}$. a FoG correlates with the proportion of colonies that grow on $10 \mu \mathrm{g} / \mathrm{ml} \mathrm{FLC} \mathrm{relative} \mathrm{to} \mathrm{growth} \mathrm{on} \mathrm{plates} \mathrm{without} \mathrm{drug.} \mathrm{Black} \mathrm{dots} \mathrm{are} \mathrm{additional} \mathrm{strains} \mathrm{from}$ Fig. 1c. b Microcolony analysis at supra-MIC concentrations of FLC $(10 \mu \mathrm{g} / \mathrm{ml})$. Symbols indicate cells that have stopped dividing in the presence of drug over $24 \mathrm{~h}$, scale bars $=100 \mu \mathrm{m}$. On average, strain AM2 formed fewer microcolonies than strain SC5314, but these were larger than those formed by SC5314. Time-lapse videos are available as Supplementary Movies 1-4. c, d Growth rate analysis of cells growing at supra-MIC FLC (10 $\mu \mathrm{g} / \mathrm{ml})$ during 0-5 $\mathrm{h}(\mathbf{c})$ and $10-15 \mathrm{~h}(\mathbf{d})$. e Schematic of ScanLag analysis ${ }^{75}$ that measures time of colony appearance (ToA), colony growth rate, and colony size using desktop scanners. $\mathbf{f}$ ToA on medium without drug (blue) or with $10 \mu \mathrm{g} / \mathrm{ml} \mathrm{FLC} \mathrm{(red)} \mathrm{for} \mathrm{resistant} \mathrm{isolate} \mathrm{T101,} \mathrm{and} \mathrm{isolates} \mathrm{with} \mathrm{different} \mathrm{FoG} \mathrm{levels.} \mathrm{Graphs}$ show the number of colonies ( $y$-axis) at each time point ( $x$-axis). Additional isolates are included in Supplementary Fig. 4. $\mathbf{g}$ Correlation between FoG 20 and the difference $(\Delta)$ in the ToA of colonies in the presence vs. absence of FLC ( $\Delta$ ToA $=$ ToA with FLC - ToA without FLC). Black dots are additional strains from Fig. 1c. $\mathbf{h}$ Cells that grow within the zone of inhibition are viable, as seen by replica plating of disk diffusion assays grown on casitone without FLC and incubated at $30^{\circ} \mathrm{C}$ for $48 \mathrm{~h}$. For all panels, $n \geq 2 ;{ }^{\star \star \star} P<0.001$; error bars denote standard deviations 


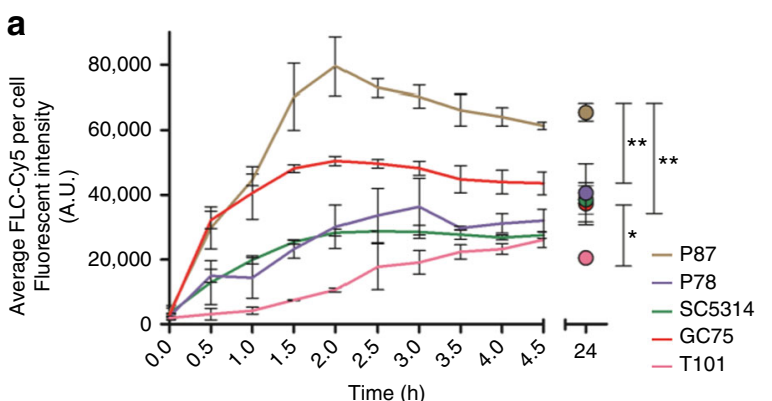

d

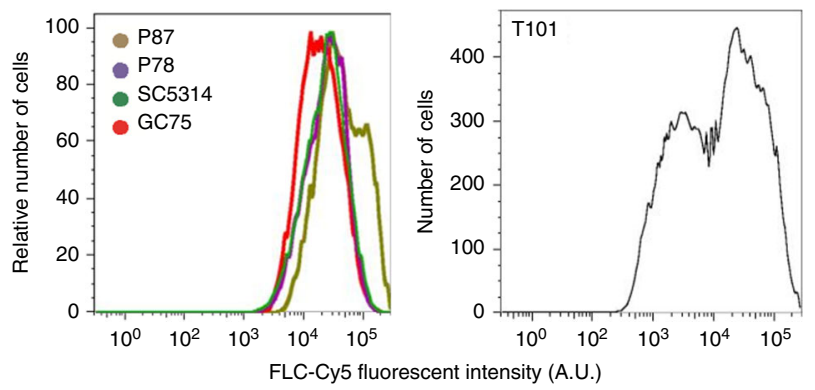

f

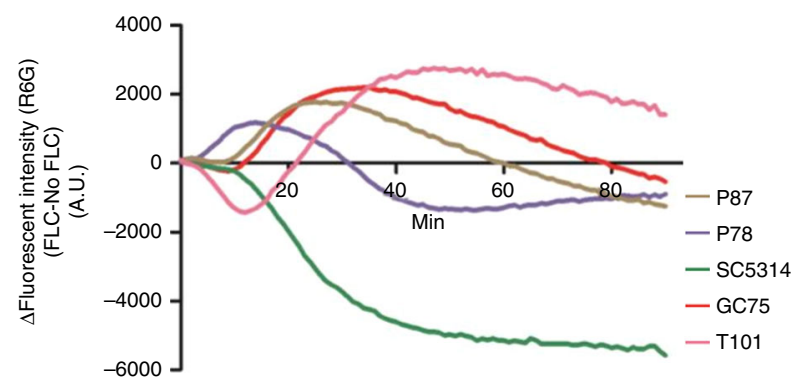

b

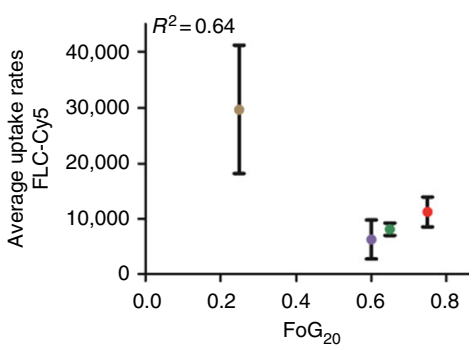

C

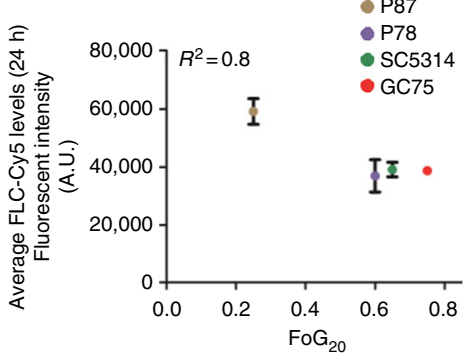

e
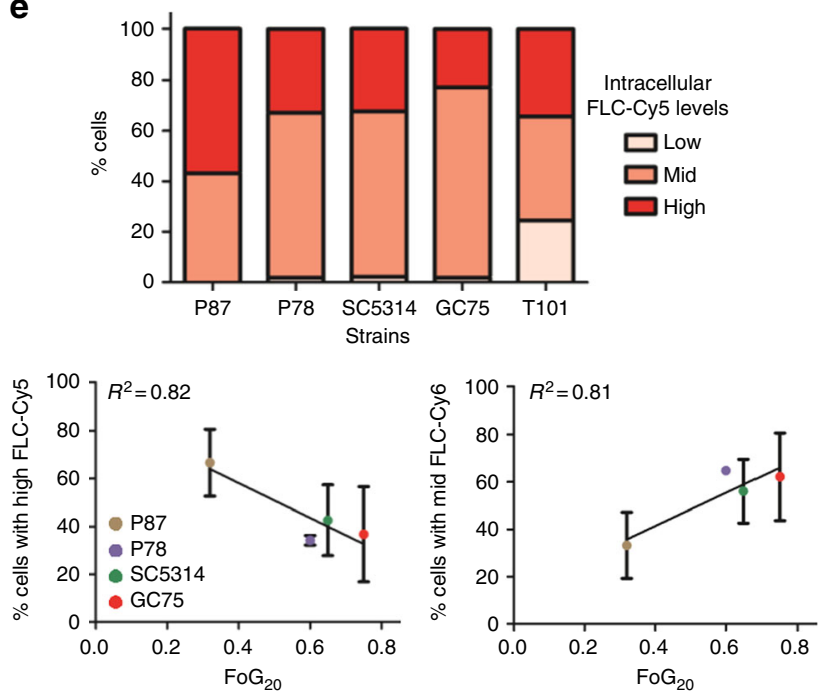

g

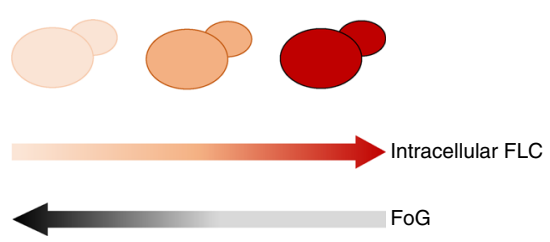

Fig. 3 Uptake, efflux and steady-state intracellular concentrations of FLC-Cy5. a Average intracellular FLC-Cy5 uptake per cell. Uptake curves for 0-5 h and for steady-state FLC-Cy5 per cell at $24 \mathrm{~h}$ measured by flow cytometry. b, c Correlation between FoG 20 and uptake rate of FLC-Cy5 between 0.5 and $1.5 \mathrm{~h}$ (b) and intracellular FLC-Cy5 at $24 \mathrm{~h}$ (c).d Intracellular FLC-Cy5 fluorescent intensity at $24 \mathrm{~h}$ for four strains with similar MIC and diverse FoG levels (left) and for the resistant strain T101 (right) normalized for number of cells ( $n=15863$ for P87, 15075 of P78, 22406 for SC5314, 18186 for GC75). e The proportion of cells (\%) with FLC-Cy5 levels at $24 \mathrm{~h}$ was divided into thirds: Low (391-422 A.U.), Mid (3912-34,643 A.U.), and High (3.5 × $10^{4}-3.14 \times 10^{5}$ A. U.) (upper panel). Proportion of cells (\%) with high (lower left panel) or mid (lower right panel) intracellular FLC-Cy5 concentration at $24 \mathrm{~h}$ vs. FoG 20 levels of the strains. $f$ Efflux of Rhodamine $6 G$ (R6G) normalized by culture density $\left(O D_{600}\right)$. Efflux curves represent data from one (of two) experiment and the curves show fluorescence intensity recorded over $90 \mathrm{~min}$ and calculated as follows: $\Delta[\mathrm{FLC}$ (with glucose - without glucose) - no drug(with glucose - without glucose)]. $\mathbf{g}$ Cartoon illustrates the steady-state drug levels in cells with high to low FoG levels. For all panels, $n \geq 2 ;{ }^{\star \star} P<0.01 ;{ }^{\star} P<0.05$, error bars denote standard deviations

unfolded protein response pathway; ${ }^{47,48}$ fluoxetine, a serotonin inhibitor; ${ }^{49}$ and FNZ, an antipsychotic drug that stimulates ABC transporter expression and indirectly inhibits calcineurin via calmodulin ${ }^{14,50}$. FLC + adjuvant cleared tolerance for all seven clinical isolates tested (Fig. 4a, b), as well as for a longitudinal series from a single HIV patient ${ }^{51}$ that had acquired resistance over time, and for a set of persistent and NP clinical isolates (Supplementary Fig. 7a-d). Importantly, most adjuvants had little or no effect on RAD/MIC levels (Fig. $4 \mathrm{a}, \mathrm{b}$ and Supplementary Fig. $7 \mathrm{a}-\mathrm{d}$ ), and thus are not expected to affect resistance in standard susceptibility assays ${ }^{52}$.

Hsp90-dependent responses affected tolerance and not susceptibility/resistance measured as MIC (at $24 \mathrm{~h}$ ). Consistent with this, the effects of temperature and Hsp90 inhibitors correlated well with FoG $\left(R^{2}=0.93\right.$, Supplementary Fig. 7e) and only partially with RAD $\left(R^{2}=-0.61\right.$, Supplementary Fig. $\left.7 \mathrm{f}\right)$. Thus, temperature inhibition of $\mathrm{Hsp} 90$ affects tolerance and not resistance per se. Furthermore, FoG levels were not affected by Hsp90 steady-state protein levels, as the amount of Hsp90 did not correlate with FoG $\left(R^{2}=0.07\right.$, Supplementary Fig. $\left.7 \mathrm{~g}\right)$. Because inhibitors of calcineurin and Hsp90 are known to affect FLC cidality $^{10,12,13,28,32}$, we asked whether other adjuvant drugs have a similar effect. All tested combinations were cidal (Fig. 4c and Supplementary Fig. 7h), indicating they have a profound effect on cell viability at supra-MIC FLC concentrations and implying that stress pathways make essential contributions to tolerance.

Consistent with the adjuvant drug responses, genes involved in several pathways, including calcineurin ${ }^{53}$ and PKC signaling ${ }^{44}$, 
primarily affected FoG and not RAD (Fig. 4d, Supplementary Fig. 8, detailed information on genes tested in Supplementary Notes 2-4 and Supplementary Tables 2 and 3). UPC2, which encodes a major transcriptional regulator of ergosterol biosynthesis ${ }^{54}$, affected both RAD and FoG levels significantly, while two regulators of efflux pump transcription had no significant effect, consistent with the redundancy of efflux mechanisms ${ }^{55}$ (Fig. 4e). In addition, IRO1 (Supplementary Note 2), which is involved in iron homeostasis ${ }^{26}$, and VPS21, which is involved in vacuolar trafficking ${ }^{19}$, affected FoG and not RAD. Thus, many genetic pathways affect the ability of subpopulations of cells to grow in the presence of supra-MIC
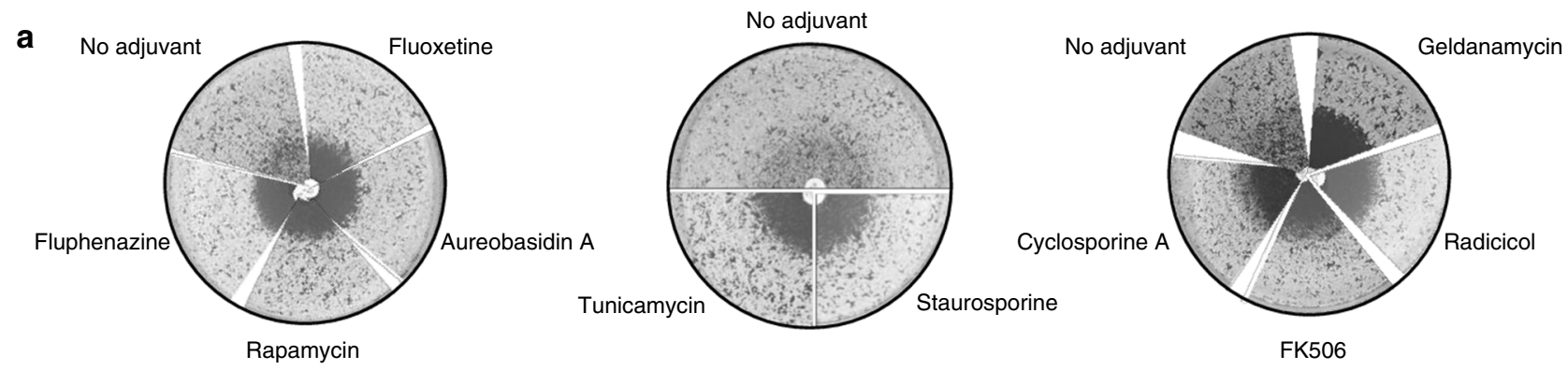

b
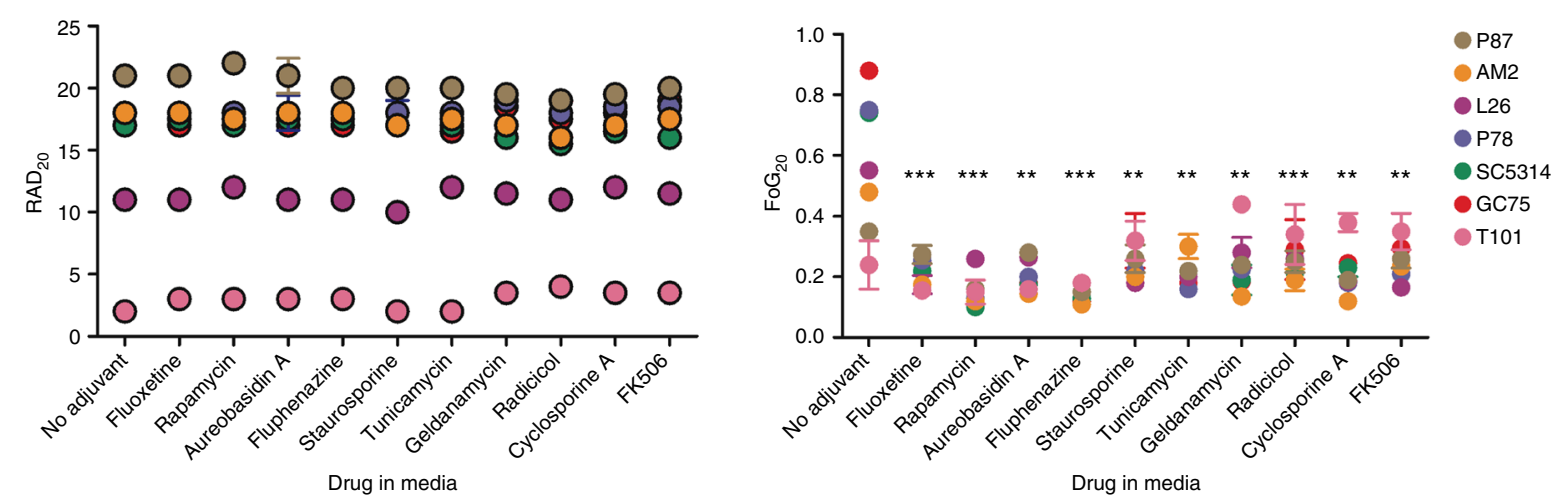

C

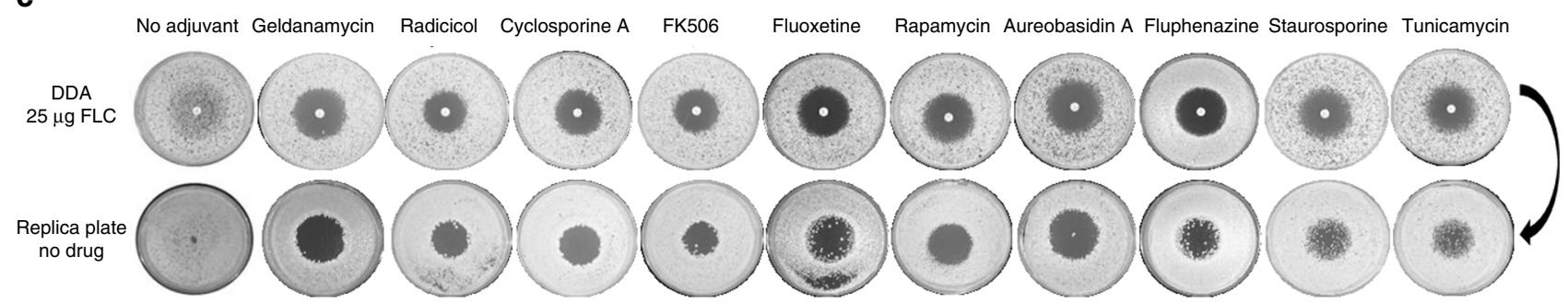

d

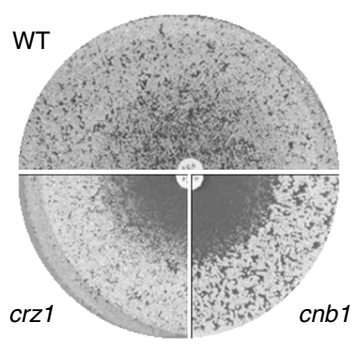

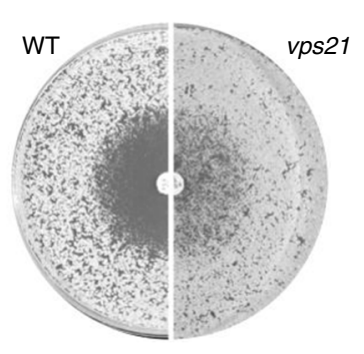

e
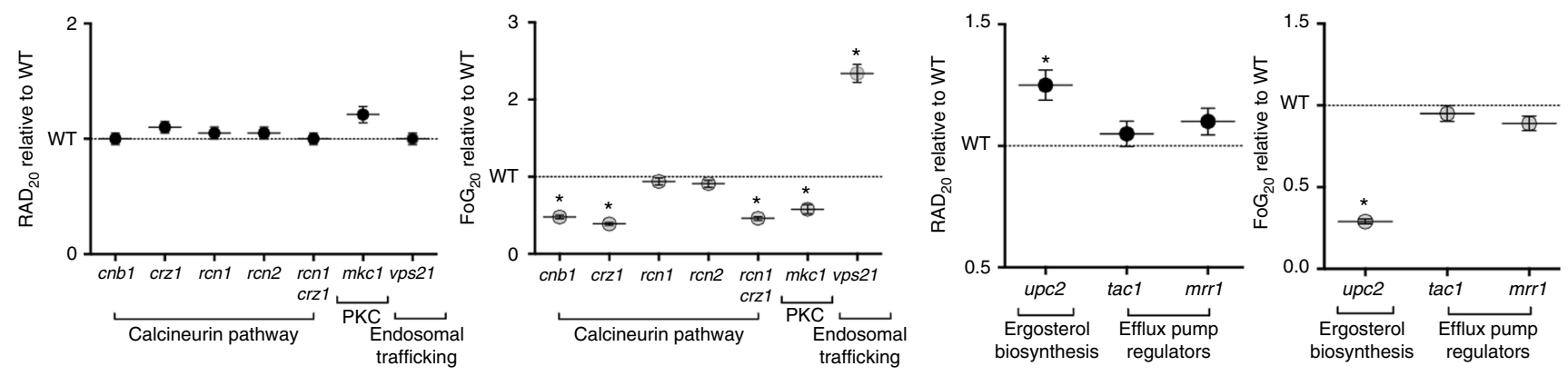
FLC concentrations, including Hsp90-dependent and Hsp90independent responses that are due to tolerance rather than resistance.

Adjuvant drugs improve FLC efficacy against high FoG strains in vivo. Given that the beneficial effects of adjuvant drugs are more evident on high FoG strains, we asked if adjuvant therapy would distinguish between levels of tolerance in an infection model. Galleria mellonella larvae were used to test potential in vivo differences between isolates with different tolerance levels, both with respect to their ability to cause disease and with their ability to respond to therapy with FLC alone or FLC plus the adjuvant FNZ $^{56}$ (Fig. 4a). A series of isolates was derived by passaging the SC5314 strain in the presence or absence of FLC. The resulting isolates had indistinguishable RAD but distinct FoG levels relative to the parental strain (Supplementary Fig. 9a and Supplementary Data 1).

G. mellonella larvae infected with fungal cells were treated with either phosphate-buffered saline (PBS) (control), FLC, or combination therapy (FLC and FNZ) (Fig. 5a). SC5314 and derived strains with similar FoG levels killed all larvae within 9-14 days. Importantly, these lower FoG isolates had similar responses to FLC and to the FLC + FNZ combination: they rescued up to $17 \%$ of the infected larvae (Fig. 5b, c and Supplementary Fig. 9b). By contrast, high FoG strains displayed delayed killing and decreased virulence in the larvae, and did not respond to FLC alone (Fig. 5d and Supplementary Fig. 9b). Notably, the FLC + FNZ combination significantly improved the outcomes for high FoG strains relative to FLC alone and PBS-control groups: larval death was delayed and up to $50 \%$ of larvae infected with high FoG strains survived the experiment (Fig. 5d and Supplementary Fig. 9b). Similar results were obtained with a low FoG clinical isolate (readily cleared by FLC therapy) when compared with a high FoG isolate (that persisted in the bloodstream during multiple rounds of FLC therapy) (Supplementary Fig. 9c). Presumably, FLC + FNZ significantly decreased larval killing by rendering FLC cidal for those cells growing at supra-MIC concentrations. Thus, in vivo responses to azoles and to combination therapies differed for different isolates according to their tolerance levels.

Persistent candidemia is associated with highly tolerant isolates. Echinocandins are considered the optimal line of therapy for patients with candidemia, yet FLC remains a frontline drug for systemic $C$. albicans infections, especially in low income countries ${ }^{57}$. Treatment with FLC often fails despite isolates being drug susceptible when tested in vitro, and rates of persistent candidemia are often higher in patients treated with FLC rather than with echinocandins ${ }^{58}$. To examine possible connections between susceptibility and tolerance levels, we collected sets of clinical isolates from patients with candidemia that were either efficiently cleared by a single course of FLC treatment (NP) or that persisted in the host despite extended FLC therapy (Fig. 6a, Supplementary Fig. 10a, see detailed isolate description in Methods and Supplementary Data 2).

The drug responses of persistent and NP isolates and several control strains displayed similar RAD and MIC levels $(0.25-1 \mu \mathrm{g} /$ $\mathrm{ml}$ ), well below those of resistant strains (clinical MIC breakpoint $=4 \mu \mathrm{g} / \mathrm{ml}$ ), when assayed at both 24 and $48 \mathrm{~h}$ (Fig. $6 \mathrm{~b}$ and Supplementary Fig. 10b, c). Strikingly, FoG/SMG levels differed significantly between the two groups of clinical isolates, especially when compared at $48 \mathrm{~h}$ (Fig. $6 \mathrm{~b}, \mathrm{c}$ ) and, as expected, correlated well with one another (Supplementary Fig. 10d, $R^{2}=0.62$ ). Importantly, persistent candidemia isolates displayed higher FoG/ SMG levels than those readily cleared upon FLC treatment. In fact, many persistent isolates had FoG levels higher than 0.5, indicating that over half of the cells in the population could grow, albeit slowly, in the presence of FLC (Fig. 6b). Taken together, these experiments demonstrate that tolerance is an intrinsic property distinct from drug susceptibility, and that tolerance levels correlate with infections that resist azole treatment in the clinic.

\section{Discussion}

Currently, decisions about therapeutic strategies to treat Candida infections are based upon patient status, infecting species, and antifungal susceptibility, with clinical MIC assays designed to avoid the detection of tolerance ${ }^{22,52}$. Here, quantification and characterization of tolerance across $C$. albicans isolates found that many of them exhibit tolerance, defined as the ability of a subpopulation of cells to grow slowly at supra-MIC concentrations. Tolerance is related to phenomena previously described as "trailing growth"19,22-24,32,33,59, "tolerance"5,26,60, or Hsp90dependent "resistance"10,28,44,61. Studying growth dynamics and quantifying tolerance revealed that it is: (1) a subpopulation effect and the size of the subpopulation is stable; (2) due to slow growth in drug stress; (3) correlates with intracellular drug levels; (4) dependent upon stress response pathways, and (5) mechanistically distinct from resistance. Several adjuvants completely cleared FoG without altering susceptibility (MIC) and, when combined with the fungistatic drug FLC, yielded a fungicidal cocktail. Consistent with this, combination therapy was most effective in vivo at treating infections by high tolerance strains, whereas the adjuvant did not improve FLC efficacy against low FoG isolates. Furthermore, C. albicans isolates that cause persistent candidemia exhibited significantly higher tolerance than isolates readily cleared by FLC. Thus, quantitatively measuring tolerance levels of infecting isolates may provide important prognostic insights concerning both the success of FLC therapy and the potential efficacy of combination therapies.

The subpopulation effect of tolerance is readily detected on agar plate assays, where individual cells and their clonal progeny are evident; in liquid assays, cells are mixed and subpopulation

\footnotetext{
Fig. 4 Adjuvant drugs significantly reduce FLC tolerance but not resistance and render FLC cidal. a Disk diffusion assays performed with $25 \mu \mathrm{F}$ FL on casitone plates supplemented with adjuvant drugs $20 \mu \mathrm{g} / \mathrm{ml}$ fluoxetine, $5 \mathrm{ng} / \mathrm{ml}$ aureobasidin $\mathrm{A}, 0.5 \mathrm{ng} / \mathrm{ml} \mathrm{rapamycin,} 10 \mu \mathrm{g} / \mathrm{ml} \mathrm{fluphenazine,} 12.5 \mathrm{ng} / \mathrm{ml}$ staurosporine, $0.25 \mu \mathrm{g} / \mathrm{ml}$ tunicamycin, Hsp90 inhibitors $(0.5 \mu \mathrm{g} / \mathrm{ml}$ geldanamycin and $0.5 \mu \mathrm{g} / \mathrm{ml}$ radicicol), and calcineurin inhibitors $(0.5 \mu \mathrm{g} / \mathrm{ml} \mathrm{FK} 506$ and $0.4 \mu \mathrm{g} / \mathrm{ml}$ cyclosporine A) shown for strain SC5314. b RAD and FoG levels performed on disk diffusion assays with FLC and adjuvants. c Effect of drug adjuvants and pathways inhibitors on the viability of cells growing inside the zone of inhibition. FLC disk diffusion assays of SC5314 without or with adjuvant were replica plated (after removal of the drug disk) onto casitone plates (without FLC or adjuvants) and incubated at $30{ }^{\circ} \mathrm{C}$ for $48 \mathrm{~h}$. $\mathbf{d}$, e FLC disk diffusion assays performed using a series of mutants carrying deletions in genes encoding the calcineurin subunit Cnb1, the calcineurin-responsive transcription factor $\mathrm{Crz1}$, calcineurin regulators Rcn1 and Rcn2, MAP kinase Mkc1, vacuolar trafficking protein Vps21 (d), ergosterol biosynthesis regulator Upc2, and efflux pump regulators Tac1 and Mrr1 (e). These mutants as well as the rcn1 crz1 double mutant were analyzed by disklmageR, and RAD and FoG levels are shown relative to the isogenic parental strains (WT). All pictures in this figure are representative of two biological replicates, asterisks denote significant differences relative to corresponding parental strains. For all panels, $n \geq 2 ;{ }^{\star \star \star} P<0.001 ;{ }^{\star \star} P<0.01 ;{ }^{\star} P<0.05$, error bars denote standard deviations
} 
a

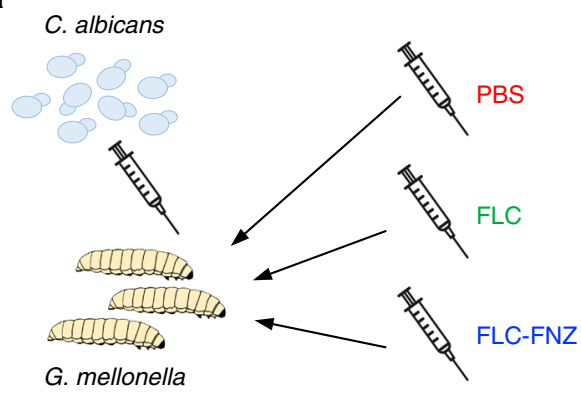

C

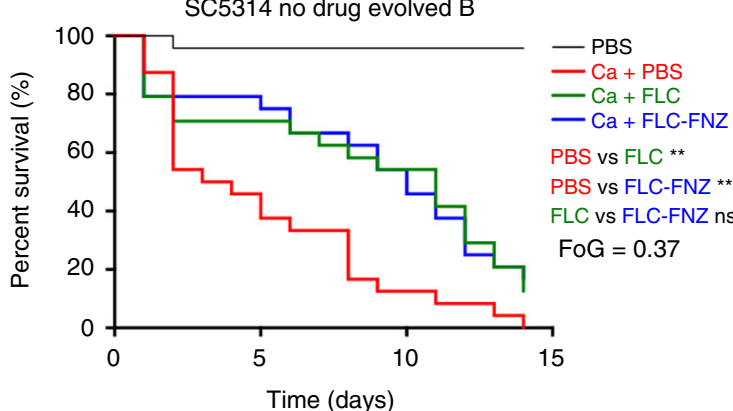

b

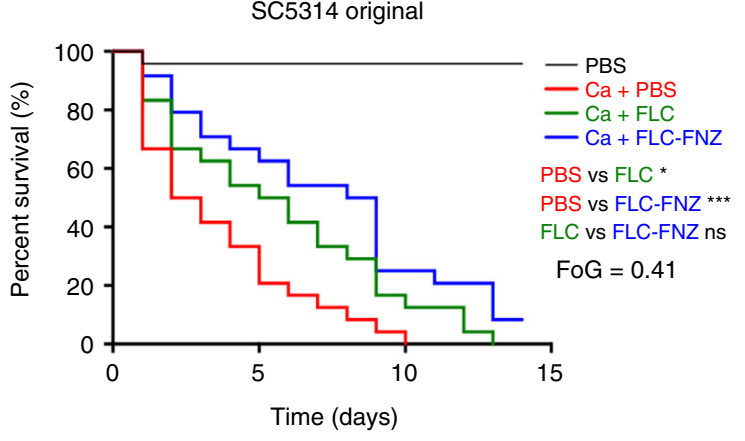

d

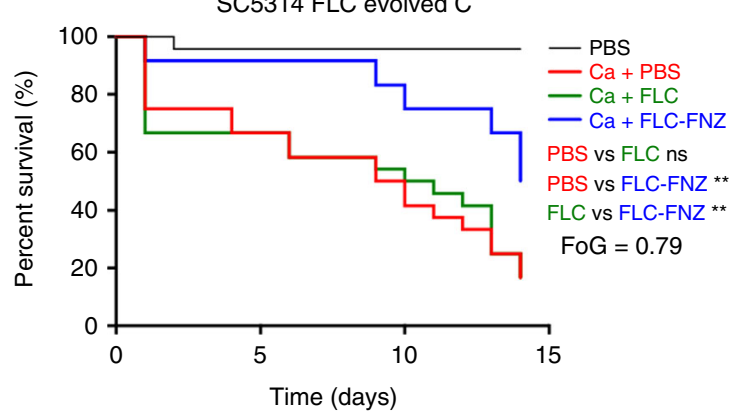

Fig. 5 Combination therapy partially rescues systemic infection of G. mellonella by high FoG C. albicans isolates. a G. mellonella larvae were injected with $3 \times$ $10^{5}$ yeast cells/larvae followed by a second injection with either PBS, FLC alone, or FLC and FNZ within 90 min of the first injection. b-d Survival curves of larvae infected with SC5314 (b), low FoG (c) and high FoG (d) isogenic derivatives. Each curve represents a group of 24 larvae $(n=24)$ which were monitored daily for survival for up to 14 days after infection. $P$ values represent results of log-rank test comparing different treatment conditions with significance values as follows: ${ }^{\star \star \star} P<0.001$; ${ }^{\star \star} P<0.01$; ${ }^{\star} P<0.05$; ns nonsignificant

effects are more difficult to distinguish. Growth dynamics in colonies $^{35}$, microcolony formation ${ }^{62}$, and liquid growth assays all suggest tolerance correlates with the degree of growth after drug exposure. This implies that a subpopulation of cells is inherently more able to adapt to the drug than the rest of the population. We do not rule out the possibility that aneuploidy could contribute to tolerance in some strains; however, isolates analyzed here include those with euploid genomes yet a wide range of tolerance levels ${ }^{63,64}$. It is therefore unlikely that aneuploidy represents the main mechanism underlying tolerance. Moreover, the fact that tolerance occurs in a subpopulation of cells and that the size of this subpopulation is retained when cells are retested also argues against aneuploidy being a major driver of tolerance. Since the size of such subpopulations is stable (FoG levels do not change with extended passaging in the absence of FLC) tolerance is predicted to be a function of cell physiology and environmental responsiveness that differs between genetic backgrounds and growth conditions.

We show that isolates with higher tolerance levels have more cells with lower intracellular drug levels, but that tolerance is not a function of either uptake or efflux rates, despite the well-known role of efflux in drug resistance ${ }^{65-69}$. The factors other than uptake and efflux that impact intracellular FLC levels remain to be determined. SC5314-derived high FoG isolates also appeared to be less virulent than isogenic low FoG strains when no drugs were administered (Fig. 5c, d and Supplementary Fig. 9b), although this correlation was not evident for the non-isogenic persistent vs. NP clinical isolates (Supplementary Fig. 9c). We speculate that, similar to drug resistance, tolerance may exact a fitness cost on strains growing in the absence of drug and that compensatory mutations may alleviate these costs in some strains.

A novel insight from this work is that inhibitors of cellular stress pathways improve FLC efficacy primarily via their effect on tolerance and not resistance. This has two important implications. First, the subpopulation nature of tolerance suggests that these stress pathways must exhibit cell-to-cell variation. Second, the contributions of stress response pathways differ considerably between isolates, albeit in a manner that maintains population heterogeneity (and the size of the tolerant subpopulation) as a heritable feature of the given strain. Tolerance is clearly related to the Hsp90-dependent response and distinct from bona fide resistance. Hsp90 and calcineurin are well known to affect fungal drug responses, including the cidality of azoles $26,32,42,43,70,71$. How the TOR pathway, the unfolded protein response, PKC signaling, sphingolipid synthesis, and iron homeostasis, as well as fluoxetine and FNZ affect drug responses and increase FLC cidality remains to be determined.

The distinction between resistance and tolerance is consistent with the mechanisms that impact them: resistance mechanisms directly affect the drug target or its concentration in the cell, thereby enabling efficient growth in the presence of the drug 9 . By contrast, tolerance reflects stress response strategies that are indirect and may enable survival despite the continued ability of the drug to interact with its target, to remain in the cell (albeit at lower average concentrations) and to affect cell growth. Stress responses can modulate physiology, for example, membrane $e^{72}$ or cell wall integrity ${ }^{73}$ and the aggregation of proteins into stress granules or other physiological switches ${ }^{74}$, thereby minimizing deleterious cellular responses to the drug.

The growth properties of cells at supra-MIC concentrations measured here with FLC, a fungistatic drug, contrast with those measured for antibacterial tolerance in bactericidal drugs. This likely reflects distinct modes of action between static and cidal drugs, as well as different molecular mechanisms of stress responses in eukaryotes and bacteria. Antibacterial tolerance generally involves a longer lag phase for the majority of the 
a

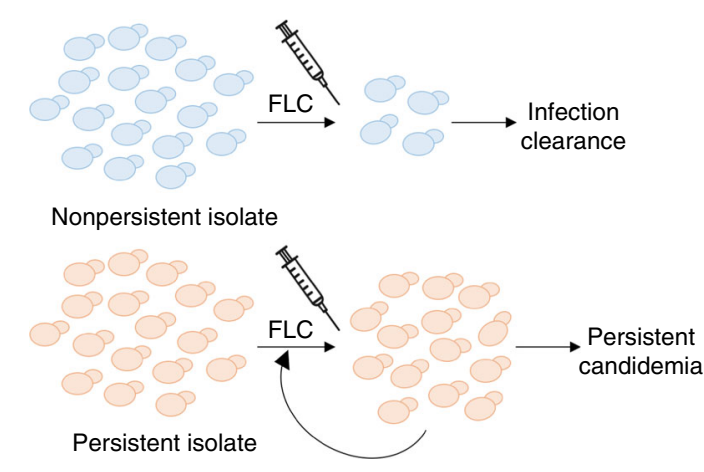

b

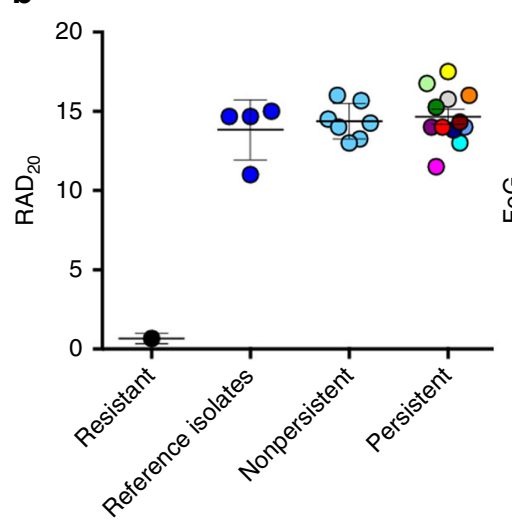

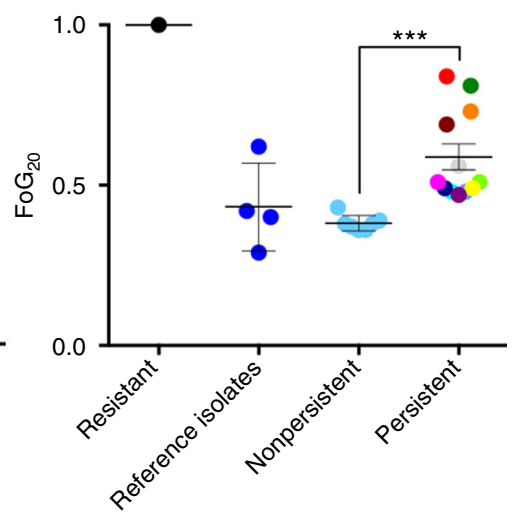

$\mathrm{SMG}$ at $24 \mathrm{~h}$
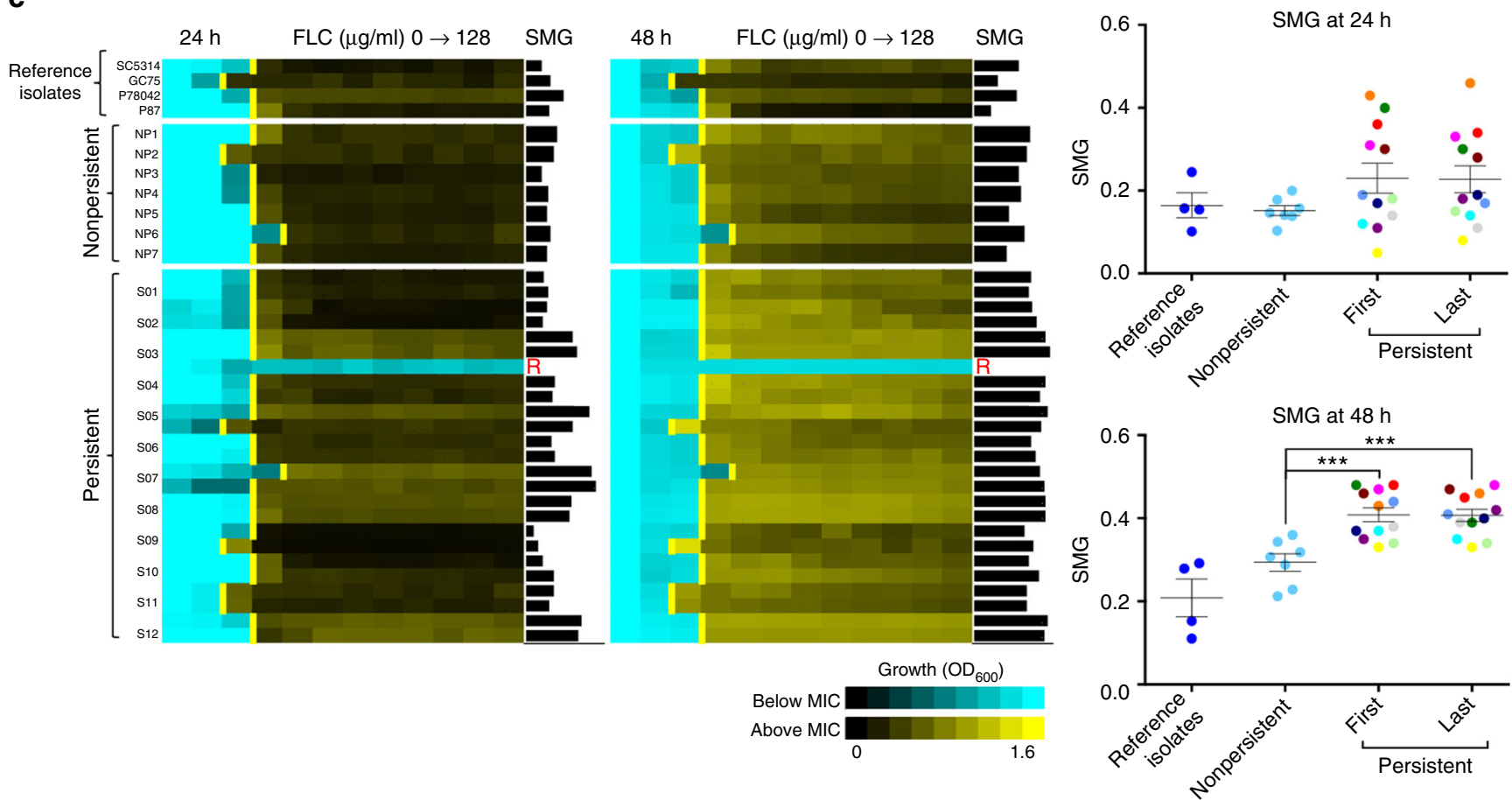

Fig. 6 FoG and SMG levels differ between persistent and non-persistent isolates. a Candida albicans isolates from bloodstream infections were either efficiently cleared by a single course of FLC treatment (non-persistent) or persisted in the host despite multiple rounds of FLC therapy. $\mathbf{b}$ FoG and RAD levels for isolates SC5314, GC75, P78042, and P87 (reference isolates studied in Figs. 1-5), resistant $(R, n=1)$ isolate P60002 31 , the non-persistent isolates (NP, $n=7)$, and only the first patient isolate from each of the series of clinically persistent strains $(P, n=12)$. Asterisks indicate significant differences between persistent and non-persistent isolates ( $t$ test, ${ }^{\star \star \star} P<0.001$ ). c Broth microdilution assays showing MIC and SMG levels at 24 and $48 \mathrm{~h}$ for the susceptible control strains, the non-persistent isolates as in $\mathbf{b}$ and for both the first and last isolates for each of the 12 clinically persistent series (S01-12). The final isolate of the S03 series of persistent strains had become FLC-resistant (MIC >128 $\mu \mathrm{g} / \mathrm{ml}$, Supplementary Fig. 10a), and therefore the penultimate isolate, which remained susceptible, was used across analyses. Asterisks indicate significant differences between persistent and nonpersistent isolates $\left(t\right.$ test, ${ }^{\star \star \star} P<0.001$ ). For all panels isolates were tested in three or more biological replicates, error bars denote standard deviations

population $^{36}$. By contrast, antifungal tolerance involves the earlier appearance of a subpopulation of cells that continue to grow in the presence of drug and, unlike "phenotypic resistance" described for bacteria ${ }^{75}$, is not dependent upon growth phase or cell density.

This study revisited the question of whether supra-MIC growth is clinically relevant and, by inference, whether the stress pathways that mediate it represent important drug targets. Previous work suggested that trailing growth was not important for virulence in either mouse models ${ }^{76}$ or infection outcomes in the human host $\mathrm{t}^{21}$. However, these studies analyzed short-term responses, rather than persistence or recurrence of Candida infection over longer time frames. Here, both in vivo and clinical studies provide a proof of principle suggesting that retrospective and prospective clinical studies that measure tolerance are warranted. We posit that monitoring FoG/SMG, in addition to RAD/ MIC, in standard clinical assays may have prognostic value for the likelihood of a persistent infection, for the responsiveness of a given isolate to FLC, as well as for the synergism of an adjuvant drug with FLC. Furthermore, in developing countries where azoles remain the major antifungals in use, measuring tolerance, in addition to susceptibility, may be especially relevant for predicting clinical outcomes and the addition of low cost adjuvant drugs could significantly impact treatment efficacy. 
Understanding the contribution of tolerance to the progression of fungal infections not only can provide fundamental insights into the biology of fungal subpopulation behaviors but also has the potential to inform clinical practices.

\section{Methods}

Candida albicans isolates. All strains (Supplementary Data 1) were streaked onto rich media (YPD) plates and grown for $24 \mathrm{~h}$ at $30^{\circ} \mathrm{C}$. A single colony from each strain was arbitrarily selected and frozen in $50 \%$ glycerol and stored at $-80^{\circ} \mathrm{C}$ for all assays. For each mutant tested, we used genetically matched parental control strains and, where appropriate, nutrient supplements were used to compensate for auxotrophies.

Isogenic SC5314 low and high FoG isolates were obtained by sequentially passaging SC5314 every $24 \mathrm{~h}$ in YPD (1/100 dilutions, $~ 84$ generations) either with or without $1 \mu \mathrm{g} / \mathrm{ml} \mathrm{FLC.} \mathrm{Persistent} \mathrm{and} \mathrm{NP} \mathrm{clinical} \mathrm{isolates} \mathrm{were} \mathrm{obtained} \mathrm{from}$ patients with candidemia that were investigated by one of us (A.L.C.) during several candidemia surveys ${ }^{77}$. Fungal isolates were obtained from two groups of patients: patients with a single episode of candidemia, for which infection was resolved after the first course of antifungal therapy, and patients with persistent candidemia. Persistent candidemia was defined here as two or more blood cultures positive for C. albicans, on one or more days apart, despite at least 3 days of antifungal therapy with FLC. NP isolates (NP1-7) were cleared from the bloodstream soon after FLC treatment was initiated and treatment was continued for an average of 16 days. In contrast, persistent infections in 12 patients yielded serial isolates both prior to and throughout the course of treatment, with 3 to 9 isolates per patient treated for an average of 20 days (P, S01-S12, Supplementary Fig. 10a). Persistent candidemia in these patients occurred despite clinical MIC assays having established that all isolates were FLC susceptible, with MIC levels $<1$ $\mu \mathrm{g} / \mathrm{ml}$. While each patient had distinct clinical backgrounds and trajectories, the two groups were matched in terms of age, underlying conditions, time of central venous catheter removal, and first line of antifungal therapy. Patients received intravenous FLC as first line of therapy and the initial time of therapy did not differ between persistent and NP infections. In some cases of persistent candidemia, antifungal therapy was continued with either caspofungin or amphotericin $B$ (Supplementary Fig. 10a). Of the 19 patients, 7 patients died during the 30-day follow-up, 6 of which were unable to clear the fungal infection, although causality between infection and death could not be determined. Isolates from patients with active cancer under chemotherapy, neutropenia, endocarditis, deep-seated Candida infections, corticosteroid, or other immunosuppressive drug exposure were excluded from the study. All ethical regulations of patient privacy, sample collection, and handling were observed and the study was approved by the Ethical Committee of the Federal University of São Paulo (January, 2016, No. 9348151215).

Strain construction. To disrupt the two alleles of the $R C N 2$ gene, we amplified (using primers BP1440 and BP1441, Supplementary Table 4) the flanking sequence of ORF C7_01700W using BJB-T 2 (HIS1) and BJB-T 61 (ARG4) plasmids as a template (Supplementary Table 4). Strain YJB-T65 was transformed with this PCR product to generate heterozygote mutant YJB-T 2214 ( $r$ cn2::HIS1) and subsequently homozygote mutant YJB-T2227 (rcn2::HIS1/rcn2::ARG4). The disruptions were verified using primers BP1444 and BP1445.

Broth microdilution assays. MIC for each strain was measured using CLSI M27A2 guidelines with minor modifications as follows. Strains were streaked from glycerol stock onto YPD agar and grown for $24 \mathrm{~h}$ at $30^{\circ} \mathrm{C}$. Colonies were suspended in $1 \mathrm{ml}$ PBS and diluted to $10^{3}$ cells $/ \mathrm{ml}$ in a 96-well plate with casitone containing a gradient of two-fold dilutions per step of FLC, with the first well contain no drug. For persistent and NP clinical isolates, cells were grown overnight in YPD at $30^{\circ} \mathrm{C}$ and diluted to $10^{4} \mathrm{cells} / \mathrm{ml}$ in YPD containing a gradient of twofold dilutions per step of FLC. MIC ${ }_{50}$ levels were determined after $24 \mathrm{~h}$ or $48 \mathrm{~h}$ by taking an optical density reading $\left(\mathrm{OD}_{600}\right)$ by a Tecan plate reader (Infinite F200 PRO, Tecan, Switzerland). MIC 50 levels (shown as yellow lines on broth microdilution assays heatmaps) were determined as the point at which the $\mathrm{OD}_{600}$ had been reduced by $\geq 50 \%$ compared to the no-drug wells.

Disk diffusion assays. The CLSI M44-A2 guidelines for antifungal disk diffusion susceptibility testing were followed with slight modifications. In brief, strains were streaked from glycerol stocks onto YPD agar and incubated for $24 \mathrm{~h}$ at $30^{\circ} \mathrm{C}$. Colonies were suspended in $1 \mathrm{ml}$ PBS and diluted to $1 \times 10^{6}$ cells $/ \mathrm{ml}$. Cells $\left(2 \times 10^{5}\right)$ were spread onto $15 \mathrm{ml}$ casitone plates $(9 \mathrm{~g} / \mathrm{l}$ Bacto casitone, $5 \mathrm{~g} / \mathrm{l}$ yeast extract, 15 $\mathrm{g} / \mathrm{l}$ Bacto agar, $11.5 \mathrm{~g} / \mathrm{l}$ sodium citrate dehydrate and $2 \%$ glucose, $0.04 \mathrm{~g} / \mathrm{l}$ adenine, $0.08 \mathrm{~g} / \mathrm{l}$ uridine). For persistent and NP clinical isolates, cells were grown overnight in YPD and $10^{5}$ cells were spread onto $15 \mathrm{ml}$ YPD plates. To facilitate comparisons between casitone and YPD disk diffusion assays, a subset of control strains with different FoG levels were included in both types of assays (SC5314, GC75, P87). The FoG and radius of inhibition levels, referred to as FoG and RAD throughout the manuscript, represent parameters measured at $20 \%$ drug inhibition $\left(\mathrm{FoG}_{20}\right.$ and $\mathrm{RAD}_{20}$, respectively). For disk diffusion assays performed with auxotrophic strains, supplementary amino acids were added to the media $(0.04 \mathrm{~g} / \mathrm{l}$ histidine and $0.04 \mathrm{~g} / \mathrm{l}$ arginine). For disk assays with drug adjuvants, the following concentrations of drugs were used: $0.5 \mu \mathrm{g} / \mathrm{ml}$ geldanamycin, $0.5 \mu \mathrm{g} / \mathrm{ml}$ radicicol, $0.5 \mu \mathrm{g} / \mathrm{ml}$ FK506, 0.4 $\mu \mathrm{g} / \mathrm{ml}$ cyclosporine A, $20 \mu \mathrm{g} / \mathrm{ml}$ fluoxetine, $5 \mathrm{ng} / \mathrm{ml}$ aureobasidin A, $0.5 \mathrm{ng} / \mathrm{ml}$ rapamycin, $10 \mu \mathrm{g} / \mathrm{ml} \mathrm{FNZ,} 50 \mu \mathrm{g} / \mathrm{ml}$ doxycycline, $12.5 \mathrm{ng} / \mathrm{ml}$ staurosporine, and $0.25 \mu \mathrm{g} / \mathrm{ml}$ tunicamycin. A single $25 \mu \mathrm{g}$ FLC disk $(6 \mathrm{~mm}$, Oxoid, UK or Liofilchem, Italy) was placed in the center of each plate, plates were then incubated at $30^{\circ} \mathrm{C}$ for $48 \mathrm{~h}$, and each plate was photographed individually. Analysis of the disk diffusion assay was done using the diskImageR pipeline ${ }^{31}$ and the $\mathrm{R}$ script available at https:// github.com/acgerstein/diskImageR/blob/master/inst/walkthrough.R. Several controls indicated that drug in the disk is stable. First, incubation of the disk on the plate for $24 \mathrm{~h}$ prior to spreading C. albicans cells on the plate did not change FoG levels. Second, performing the assay with or without replacing the disk with a fresh disk after $24 \mathrm{~h}$ incubation also did not alter FoG levels.

ScanLag assay. The ScanLag assay was adapted from ref. ${ }^{35}$ with minor modifications. Strains were streaked from glycerol stocks onto YPD agar and incubated for $24 \mathrm{~h}$ at $30^{\circ} \mathrm{C}$. Colonies were suspended in $1 \mathrm{ml} \mathrm{PBS}$, diluted to $10^{4} \mathrm{cell} / \mathrm{ml}$, and $\sim 500$ were spread onto casitone plates with or without $10 \mu \mathrm{g} / \mathrm{ml} \mathrm{FLC} \mathrm{(Sigma-}$ Aldrich, St. Louis, MO, USA). Plates were placed on the scanners at $30{ }^{\circ} \mathrm{C}$ and scanned every $30 \mathrm{~min}$ for $96 \mathrm{~h}$. Image analysis was done in MATLAB using the "ScanLag" script ${ }^{35}$ that was adapted for yeast cells by changing the identification of the size of the colony to a minimum of 20 pixels.

Viability assays. Replica plating was performed from disk diffusion plates that were incubated at $30^{\circ} \mathrm{C}$ for $48 \mathrm{~h}$. Master plates were inverted and pressed firmly on a sterile cotton velveteen stamp and then transferred to new casitone plates containing no drug. Replica plates were incubated at $30^{\circ} \mathrm{C}$ for $48 \mathrm{~h}$, and then each plate was photographed individually.

Enzyme-linked immunosorbent assay of Hsp90. The enzyme-linked immunosorbent assay (ELISA) protocol was modified from ref. ${ }^{78}$. Briefly, C. albicans cells were grown for $6 \mathrm{~h}$ at $30^{\circ} \mathrm{C}$ with shaking $(220 \mathrm{rpm})$ in YPD with or without $10 \mu \mathrm{g} /$ $\mathrm{ml}$ FLC (Sigma-Aldrich, St. Louis, MO, USA) and harvested at exponential phase $\left(\mathrm{OD}_{600} 0.6-0.8\right)$. Cells were centrifuged for $10 \mathrm{~min}\left(3000 \mathrm{rpm}, 4^{\circ} \mathrm{C}\right)$, and washed once with ice-cold PBS. Pellets were resuspended in $200 \mu \mathrm{l}$ lysis buffer $(50 \mathrm{mM}$ HEPES, pH 7.5, $150 \mathrm{mM} \mathrm{NaCl}, 5 \mathrm{mM}$ EDTA, $1 \%$ Triton X-100, protease inhibitor cocktail (Roche Diagnostics)) together with acid-washed glass beads. Cells were then mechanically disrupted by vortexing for $30 \mathrm{~min}$ at $4^{\circ} \mathrm{C}$. Cell lysates were diluted 1:10 in PBS and subjected to BCA analysis (Pierce Biotechnology, Rockford, IL, USA) to determine protein concentrations. Cell lysates at $10 \mu \mathrm{g} / \mathrm{ml} \mathrm{con-}$ centration were incubated in 96-well ELISA plates for $18 \mathrm{~h}$ at $4{ }^{\circ} \mathrm{C}$. Wells were washed with PBST (PBS $+0.05 \%$ Tween-20), blocked with $1 \%$ skim milk in PBST for $2 \mathrm{~h}$ at $37^{\circ} \mathrm{C}$, and washed. Rabbit polyclonal anti-Hsp90 antibody (Dundee Cell Products, Scotland) was diluted 1:1000 in blocking buffer applied overnight at $4{ }^{\circ} \mathrm{C}$ Horseradish peroxidase-coupled donkey anti-rabbit IgG (1:1000 dilution, Jackson ImmunoResearch Laboratories, West Grove, PA, USA) was incubated for $1 \mathrm{~h}$ at 37 ${ }^{\circ} \mathrm{C}$ followed by washing. Detection was done with TMB $\left(3,3^{\prime}, 5,5^{\prime}\right.$-tetramethybenzidine). The reaction was terminated with $0.16 \mathrm{M}$ sulfuric acid and absorbance was measured at $450 \mathrm{~nm}$ in an ELISA plate reader.

FLC-Cy5 uptake measured by flow cytometry. Candida albicans cells were grown overnight in YPD media at $30^{\circ} \mathrm{C}$. Cultures where diluted 1:100 in $3 \mathrm{ml}$ casitone medium and incubated for $3 \mathrm{~h}$ at $30^{\circ} \mathrm{C}$. Drugs were added to a final concentration of $10 \mu \mathrm{g} / \mathrm{ml}$ for FLC and $1 \mu \mathrm{g} / \mathrm{ml}$ for FLC-Cy $5^{40}$. Cells were harvested every $30 \mathrm{~min}$ and diluted 1:4 in 50\% TE (50 mM Tris, pH 8, $50 \mathrm{mM}$ EDTA). Data were collected from 25,000 to 35,000 cells per time point using $561 \mathrm{nM} \mathrm{EX}$ and $661 / 20 \mathrm{nM} \mathrm{EM}$ in a MACSQuant flow cytometer and gated to by SSC $<10^{3} \mathrm{~A}$. U. and FSC $>10^{4}$ A.U. in (SSC vs. FSC) to eliminate small debris particles. Analysis was done using the FlowJo 8.7 software.

Efflux of R6G as measurement of drug efflux capacity. The assay was adapted from ref. ${ }^{79}$ with minor modifications. In brief, strains were streaked from glycerol stock onto YPD plates and incubated for $24 \mathrm{~h}$ at $30^{\circ} \mathrm{C}$. Colonies were resuspended in $3 \mathrm{ml}$ casitone medium and grown overnight in $30^{\circ} \mathrm{C}$. Cultures where diluted 1:100 in $5 \mathrm{ml}$ casitone medium and incubated for $3 \mathrm{~h}$ at $30^{\circ} \mathrm{C}$. Cells were centrifuged, washed in $5 \mathrm{ml} \mathrm{PBS} \mathrm{(pH} \mathrm{7),} \mathrm{and} \mathrm{resuspended} \mathrm{in} 2 \mathrm{ml}$ PBS with or without $10 \mu \mathrm{g} / \mathrm{ml}$ FLC. Cells suspensions were incubated for $1 \mathrm{~h}$ at $30^{\circ} \mathrm{C}$ and R6G (SigmaAldrich, St. Louis, MO USA) was added at $10 \mu \mathrm{g} / \mathrm{ml}$ to allow R6G accumulation (1 h). Next, cells were washed twice with PBS at $4{ }^{\circ} \mathrm{C}$, and resuspended in a final volume of $300 \mu \mathrm{l}$ PBS. Fifty microliters of individual suspensions were diluted in $150 \mu \mathrm{l}$ PBS and aliquoted into a 96-well microtiter plate. Baseline emission of fluorescence (excitation $344 \mathrm{~nm}$, emission $555 \mathrm{~nm}$ ) was recorded for $5 \mathrm{~min}$ in a Tecan plate reader at $30^{\circ} \mathrm{C}$ (Infinite F200 PRO, Tecan, Switzerland), in relative fluorescence units, and $1 \%$ D-glucose was next added to each strain to initiate R6G efflux. Negative controls contained no glucose and data points were recorded for $90 \mathrm{~min}$ in triplicates at $1 \mathrm{~min}$ intervals. 
Galleria mellonella virulence assays. G. larvae were obtained from Vanderhorst Wholesale (Saint Marys, OH, USA) and the infection protocol was adapted from $\mathrm{Li}$ et al ${ }^{80}$. Larvae were kept at $15^{\circ} \mathrm{C}$ and used within 1 week of delivery. Larvae were randomly selected for each experiment in groups of 12 and those showing signs of melanization were excluded. C. albicans inoculums were prepared from cultures grown overnight at $30^{\circ} \mathrm{C}$ in YPD and washed twice with sterile PBS. Cells were counted using a hemocytometer and adjusted to $3 \times 10^{7}$ cells $/ \mathrm{ml}$ in sterile PBS. Each larva was initially injected with $3 \times 10^{5}$ cells via the last left pro-leg using a 10 $\mu \mathrm{l}$ glass syringe and a $26 \mathrm{~S}$ gauge needle (Hamilton, 80300). A second injection with either FLC (1 mg/kg), FLC + FNZ (FNZ, $10 \mathrm{mg} / \mathrm{kg}$ ), or sterile PBS was done via the last right pro-leg $1.5-2 \mathrm{~h}$ post infection. The inoculum size was confirmed by plating of fungal cells on YPD. Infected larvae and PBS-injected controls were maintained at $37^{\circ} \mathrm{C}$ for 14 days and checked daily. Larvae were recorded as dead if no movement was observed upon contact. Virulence assays were performed with strain SC5314, with SC5314-derived isolates passaged for 12 days in either YPD alone (2 "low" FoG isolates) or YPD plus $1 \mu \mathrm{g} / \mathrm{ml}$ FLC (4 "high" FoG isolates), and with isolates NP03 and S12-01 from a clinical isolate set (see Supplementary Data 1). Experiments were performed in duplicate ( $n=24$ larvae) and statistical differences between larval groups were tested using the Mantel-Cox (log-rank) test. Negative controls included PBS, FLC alone or FLC + FNZ for groups of 24 uninfected larvae. No significant killing of larvae was observed in either of these conditions.

Growth assays. To determine growth parameters (doubling time and lag phase duration), C. albicans cells were seeded at a concentration of $2 \times 10^{5}$ cells $/ \mathrm{ml}$ into 96-well plates containing YPD media. Plates were incubated for $48 \mathrm{~h}$ at $30^{\circ} \mathrm{C}$ with continuous shaking in a Tecan plate reader (BioTek) and the optical density reading $\left(\mathrm{OD}_{600}\right)$ was recorded every $15 \mathrm{~min}$. Measurements of doubling time and lag phase duration were determined using the BioTek Gen5 software and from three biological replicates, each performed in duplicate.

Microcolony assays. Microcolony assays were adapted from ref. ${ }^{34}$ with minor modifications. Colonies were resuspended in $3 \mathrm{ml}$ casitone medium and grown overnight in $30^{\circ} \mathrm{C}$. Cultures were diluted 1:30 in casitone medium and incubated at $30^{\circ} \mathrm{C}$ until cultures reached logarithmic phase $(\sim 3-4 \mathrm{~h})$ and diluted to $10^{4}$ cells $/ \mathrm{ml}$ in casitone medium. For microscopy, glass-bottomed 24-well plates (De-GROOT, Israel) were coated with $1 \mathrm{ml}$ of a $200 \mu \mathrm{g} / \mathrm{ml}$ concanvalin A solution (Type VI, Sigma-Aldrich, St. Louis, MO, USA) for 3-4h. Wells were washed twice with $1 \mathrm{ml}$ $\mathrm{ddH}_{2} \mathrm{O}$ and $10^{4}$ cells/ml in a $2 \mathrm{ml}$ volume were added to wells with or without 10 $\mu \mathrm{g} / \mathrm{ml}$ FLC. Plates were sealed with an optically clear film (Axygen, Corning, Israel) and spun at $1200 \mathrm{rpm}$ for $1 \mathrm{~min}$. Images where captured in 100 fields per well for $48 \mathrm{~h}$ in $1 \mathrm{~h}$ intervals using a Nikon Ti Eclipse microscope equipped with a full-stage environmental chamber (set to $30^{\circ} \mathrm{C}$ ) with a Nikon Plan Apo $\times 10$ ( 0.45 numerical aperture) objective using the Nikon Elements AR software. The focusing routine utilized manual assignment for each well based on a single field. Custom software for conducting microcolony experiments, including computing and tracking microcolony areas over time was adapted from ref. ${ }^{34}$. Specific growth rates were calculated for $1500-5000$ colonies per $\operatorname{strain}^{34}$ by regressing the natural log of microcolony area over time. Growth rates were calculated separately for two time intervals $\left(0-5 \mathrm{~h}\right.$ and $10-15 \mathrm{~h}$ ) and required to have an $R^{2}>0.9$. Replicate wells (three per condition) were consistent and growth rate distributions were pooled.

Statistical analyses. All experiments represent the average of two or more biological replicates, with two technical replicates of each. Error bars represent the standard deviation. Statistical analyses were performed using two-tailed Student's $t$ tests, one-way analysis of variance and Tukey's multiple comparison tests using Microsoft Excel 2016 (Microsoft) and Prism 6 (GraphPad); $R^{2}$ tests were used for linear regressions. Significance was assigned for $P$ values $<0.05$, asterisks denote $P$ values as follows: ${ }^{* *} P<0.001 ;{ }^{* *} P<0.01 ;{ }^{*} P<0.05$.

Data availability. The authors declare that all data supporting the findings of the study are available in this article and its Supplementary Information files, or from the corresponding author upon request.

Received: 27 February 2018 Accepted: 5 June 2018

Published online: 25 June 2018

\section{References}

1. Brauner, A., Fridman, O., Gefen, O. \& Balaban, N. Q. Distinguishing between resistance, tolerance and persistence to antibiotic treatment. Nat. Rev. Microbiol. 14, 320-330 (2016).

2. Marcos-Zambrano, L. J., Escribano, P., Sanchez-Carrillo, C., Bouza, E. \& Guinea, J. Scope and frequency of fluconazole trailing assessed using EUCAST in invasive Candida spp. isolates. Med. Mycol. 54, 733-739 (2016).
3. Pfaller, M. A. \& Diekema, D. J. Progress in antifungal susceptibility testing of Candida spp. by use of Clinical and Laboratory Standards Institute broth microdilution methods, 2010 to 2012. J. Clin. Microbiol. 50, 2846-2856 (2012).

4. Doern, G. V., \& Brecher, S. M. The clinical predictive value (or lack thereof) of the results of in vitro antimicrobial susceptibility tests. J. Clin. Microbiol. 49, S11-S14 (2011).

5. Delarze, E. \& Sanglard, D. Defining the frontiers between antifungal resistance, tolerance and the concept of persistence. Drug Resist. Updat. 23, 12-19 (2015)

6. Balaban, N. Q., Gerdes, K., Lewis, K. \& McKinney, J. D. A problem of persistence: still more questions than answers? Nat. Rev. Microbiol. 11, 587-591 (2013).

7. Da Matta, D. A. et al. Multilocus sequence typing of sequential Candida albicans isolates from patients with persistent or recurrent fungemia. Med. Mycol. 48, 757-762 (2010).

8. Whaley, S. G. et al. Azole antifungal resistance in Candida albicans and emerging non-albicans Candida species. Front. Microbiol. 7, 2173 (2016).

9. Robbins, N., Caplan, T. \& Cowen, L. E. Molecular evolution of antifungal drug resistance. Annu. Rev. Microbiol. 71, 753-775 (2017).

10. Cowen, L. E., Carpenter, A. E., Matangkasombut, O., Fink, G. R. \& Lindquist, S. Genetic architecture of Hsp90-dependent drug resistance. Eukaryot. Cell 5, 2184-2188 (2006).

11. Kim, A. \& Cunningham, K. W. A LAPF/phafin1-like protein regulates TORC1 and lysosomal membrane permeabilization in response to endoplasmic reticulum membrane stress. Mol. Biol. Cell. 26, 4631-4645 (2015).

12. Robbins, N., Wright, G. D. \& Cowen, L. E. Antifungal drugs: the current armamentarium and development of new agents. Microbiol. Spectr. 4, FUNK0002-2016 (2016).

13. Cowen, L. E. et al. Harnessing Hsp90 function as a powerful, broadly effective therapeutic strategy for fungal infectious disease. Proc. Natl. Acad. Sci. USA 106, 2818-2823 (2009).

14. Sanglard, D., Ischer, F., Marchetti, O., Entenza, J. \& Bille, J. Calcineurin A of Candida albicans: involvement in antifungal tolerance, cell morphogenesis and virulence. Mol. Microbiol. 48, 959-976 (2003).

15. Zhai, B., Wu, C., Wang, L., Sachs, M. S. \& Lin, X. The antidepressant sertraline provides a promising therapeutic option for neurotropic cryptococcal infections. Antimicrob. Agents Chemother. 56, 3758-3766 (2012).

16. Pfaller, M. A. \& Diekema, D. J. Epidemiology of invasive candidiasis: a persistent public health problem. Clin. Microbiol. Rev. 20, 133-163 (2007).

17. Hammoud, M. S., Al-Taiar, A., Fouad, M., Raina, A. \& Khan, Z. Persistent candidemia in neonatal care units: risk factors and clinical significance. Int. J. Infect. Dis. 17, e624-e628 (2013).

18. Arthington-Skaggs, B. A. et al. Comparison of visual and spectrophotometric methods of broth microdilution MIC end point determination and evaluation of a sterol quantitation method for in vitro susceptibility testing of fluconazole and itraconazole against trailing and nontrailing Candida isolates. Antimicrob. Agents Chemother. 46, 2477-2481 (2002).

19. Luna-Tapia, A., Kerns, M. E., Eberle, K. E., Jursic, B. S. \& Palmer, G. E. Trafficking through the late endosome significantly impacts Candida albicans tolerance of the azole antifungals. Antimicrob. Agents Chemother. 59, 2410-2420 (2015)

20. Peters, B. M. et al. An azole-tolerant endosomal trafficking mutant of Candida albicans is susceptible to azole treatment in a mouse model of vaginal candidiasis. Antimicrob. Agents Chemother. 61, e00084-17 (2017).

21. Revankar, S. G. et al. Interpretation of trailing endpoints in antifungal susceptibility testing by the National Committee for Clinical Laboratory Standards method. J. Clin. Microbiol. 36, 153-156 (1998).

22. Coenye, T., De Vos, M., Vandenbosch, D. \& Nelis, H. Factors influencing the trailing endpoint observed in Candida albicans susceptibility testing using the CLSI procedure. Clin. Microbiol. Infect. 14, 495-497 (2008).

23. Agrawal, D., Patterson, T. F., Rinaldi, M. G. \& Revankar, S. G. Trailing endpoint phenotype of Candida spp. in antifungal susceptibility testing to fluconazole is eliminated by altering incubation temperature. J. Med. Microbiol. 56, 1003-1004 (2007).

24. Marr, K. A., Rustad, T. R., Rex, J. H. \& White, T. C. The trailing end point phenotype in antifungal susceptibility testing is $\mathrm{pH}$ dependent. Antimicrob. Agents Chemother. 43, 1383-1386 (1999).

25. Weil, $\mathrm{T}$. et al. Adaptive mistranslation accelerates the evolution of fluconazole resistance and induces major genomic and gene expression alterations in Candida albicans. mSphere 2, e00167-17 (2017).

26. Fiori, A. \& Van Dijck, P. Potent synergistic effect of doxycycline with fluconazole against Candida albicans is mediated by interference with iron homeostasis. Antimicrob. Agents Chemother. 56, 3785-3796 (2012).

27. Juvvadi, P. R., Lee, S. C., Heitman, J. \& Steinbach, W. J. Calcineurin in fungal virulence and drug resistance: prospects for harnessing targeted inhibition of calcineurin for an antifungal therapeutic approach. Virulence 8, 186-197 (2017). 
28. Cowen, L. E. \& Lindquist, S. Hsp90 potentiates the rapid evolution of new traits: drug resistance in diverse fungi. Science 309, 2185-2189 (2005).

29. MacCallum, D. M. et al. Property differences among the four major Candida albicans strain clades. Eukaryot. Cell 8, 373-387 (2009).

30. McManus, B. A. \& Coleman, D. C. Molecular epidemiology, phylogeny and evolution of Candida albicans. Infect. Genet. Evol. 21, 166-178 (2014).

31. Gerstein, A. C., Rosenberg, A., Hecht, I. \& Berman, J. diskImageR: quantification of resistance and tolerance to antimicrobial drugs using disk diffusion assays. Microbiology 162, 1059-1068 (2016).

32. Marchetti, O., Moreillon, P., Glauser, M. P., Bille, J. \& Sanglard, D. Potent synergism of the combination of fluconazole and cyclosporine in Candida albicans. Antimicrob. Agents Chemother. 44, 2373-2381 (2000).

33. Zomorodian, K. et al. In vitro susceptibility and trailing growth effect of clinical isolates of Candida species to azole drugs. Jundishapur J. Microbiol 9, e28666 (2016).

34. Levy, S. F., Ziv, N., \& Siegal, M. L. Bet hedging in yeast by heterogeneous, agecorrelated expression of a stress protectant. PLoS Biol. 10, e1001325 (2012).

35. Levin-Reisman, I., Fridman, O. \& Balaban, N. Q. ScanLag: high-throughput quantification of colony growth and lag time. J. Vis. Exp. 89, e51456 (2014).

36. Levin-Reisman, I. \& Balaban, N. Q. Quantitative Measurements of type I and type II persisters using ScanLag. Methods Mol. Biol. 1333, 75-81 (2016).

37. Alby, K. \& Bennett, R. J. Stress-induced phenotypic switching in Candida albicans. Mol. Biol. Cell. 20, 3178-3191 (2009).

38. Bensen, E. S., Clemente-Blanco, A., Finley, K. R., Correa-Bordes, J. \& Berman, J. The mitotic cyclins Clb2p and Clb4p affect morphogenesis in Candida albicans. Mol. Biol. Cell. 16, 3387-3400 (2005).

39. Bull, J. J., Vegge, C. S., Schmerer, M., Chaudhry, W. N. \& Levin, B. R. Phenotypic resistance and the dynamics of bacterial escape from phage control. PLoS ONE 9, e94690 (2014).

40. Benhamou, R. I. et al. Real-time imaging of the azole class of antifungal drugs in live Candida cells. ACS Chem. Biol. 12, 1769-1777 (2017).

41. Ben-Ami, R. et al. Heteroresistance to fluconazole is a continuously distributed phenotype among Candida glabrata clinical strains associated with in vivo persistence. $m$ Bio 7 , e00655-16 (2016).

42. Uppuluri, P., Nett, J., Heitman, J. \& Andes, D. Synergistic effect of calcineurin inhibitors and fluconazole against Candida albicans biofilms. Antimicrob. Agents Chemother. 52, 1127-1132 (2008).

43. Onyewu, C., Blankenship, J. R., Del Poeta, M. \& Heitman, J. Ergosterol biosynthesis inhibitors become fungicidal when combined with calcineurin inhibitors against Candida albicans, Candida glabrata, and Candida krusei. Antimicrob. Agents Chemother. 47, 956-964 (2003).

44. LaFayette, S. L. et al. PKC signaling regulates drug resistance of the fungal pathogen Candida albicans via circuitry comprised of $\mathrm{Mkc1}$, calcineurin, and Hsp90. PLoS Pathog. 6, e1001069 (2010).

45. Zhong, W., Jeffries, M. W. \& Georgopapadakou, N. H. Inhibition of inositol phosphorylceramide synthase by aureobasidin A in Candida and Aspergillus species. Antimicrob. Agents Chemother. 44, 651-653 (2000).

46. Chen, S. C., Lewis, R. E. \& Kontoyiannis, D. P. Direct effects of non-antifungal agents used in cancer chemotherapy and organ transplantation on the development and virulence of Candida and Aspergillus species. Virulence 2, 280-295 (2011).

47. Stefan, C. P. \& Cunningham, K. W. Kch1 family proteins mediate essential responses to endoplasmic reticulum stresses in the yeasts Saccharomyces cerevisiae and Candida albicans. J. Biol. Chem. 288, 34861-34870 (2013).

48. Tkacz, J. S. \& Lampen, O. Tunicamycin inhibition of polyisoprenyl $N$ acetylglucosaminyl pyrophosphate formation in calf-liver microsomes. Biochem Biophys. Res. Commun. 65, 248-257 (1975).

49. Gu, W., Guo, D., Zhang, L., Xu, D. \& Sun, S. The synergistic effect of azoles and fluoxetine against resistant Candida albicans strains is attributed to attenuating fungal virulence. Antimicrob. Agents Chemother. 60, 6179-6188 (2016).

50. Cyert, M. S. Genetic analysis of calmodulin and its targets in Saccharomyces cerevisiae. Annu. Rev. Genet. 35, 647-672 (2001).

51. White, T. C. Increased mRNA levels of ERG16, CDR, and MDR1 correlate with increases in azole resistance in Candida albicans isolates from a patient infected with human immunodeficiency virus. Antimicrob. Agents Chemother. 41, 1482-1487 (1997).

52. Arendrup, M. C., Cuenca-Estrella, M., Lass-Florl, C., Hope, W. \& Eucast, A. EUCAST technical note on the EUCAST definitive document EDef 7.2: method for the determination of broth dilution minimum inhibitory concentrations of antifungal agents for yeasts EDef 7.2 (EUCAST-AFST). Clin. Microbiol. Infect. 18, E246-E247 (2012).

53. Reedy, J. L., Filler, S. G. \& Heitman, J. Elucidating the Candida albicans calcineurin signaling cascade controlling stress response and virulence. Fungal Genet. Biol. 47, 107-116 (2010).

54. Vasicek, E. M., Berkow, E. L., Flowers, S. A., Barker, K. S. \& Rogers, P. D. UPC2 is universally essential for azole antifungal resistance in Candida albicans. Eukaryot. Cell 13, 933-946 (2014).
55. Morschhauser, J. et al. The transcription factor Mrrlp controls expression of the MDR1 efflux pump and mediates multidrug resistance in Candida albicans. PLoS Pathog. 3, el64 (2007).

56. Edlind, T., Smith, L., Henry, K., Katiyar, S. \& Nickels, J. Antifungal activity in Saccharomyces cerevisiae is modulated by calcium signalling. Mol. Microbiol 46, 257-268 (2002).

57. Nucci, M. et al. Epidemiology of candidemia in Latin America: a laboratorybased survey. PLOS ONE 8, e59373 (2013).

58. Andes, D. R. et al. Impact of treatment strategy on outcomes in patients with candidemia and other forms of invasive candidiasis: a patient-level quantitative review of randomized trials. Clin. Infect. Dis. 54, 1110-1122 (2012).

59. Braga-Silva, L. A. et al. Trailing end-point phenotype antibiotic-sensitive strains of Candida albicans produce different amounts of aspartyl peptidases. Braz. J. Med. Biol. Res. 42, 765-770 (2009).

60. Xu, D., Cheng, J., Cao, C., Wang, L. \& Jiang, L. Genetic interactions between Rch1 and the high-affinity calcium influx system Cch1/Mid1/Ecm7 in the regulation of calcium homeostasis, drug tolerance, hyphal development and virulence in Candida albicans. FEMS Yeast Res. 15, fov079 (2015).

61. Shapiro, R. S., Zaas, A. K., Betancourt-Quiroz, M., Perfect, J. R. \& Cowen, L. E. The Hsp90 co-chaperone Sgt1 governs Candida albicans morphogenesis and drug resistance. PLoS ONE 7, e44734 (2012).

62. Harrison, B. D. et al. A tetraploid intermediate precedes aneuploid formation in yeasts exposed to fluconazole. PLoS Biol. 12, e1001815 (2014).

63. Hirakawa, M. P. et al. Genetic and phenotypic intra-species variation in Candida albicans. Genome Res. 25, 413-425 (2015).

64. Abbey, D. A. et al. YMAP: a pipeline for visualization of copy number variation and loss of heterozygosity in eukaryotic pathogens. Genome Med. 6, 100 (2014).

65. Prasad, R., Rawal, M. K. \& Shah, A. H. Candida efflux ATPases and antiporters in clinical drug resistance. Adv. Exp. Med. Biol. 892, 351-376 (2016).

66. Holmes, A. R. et al. Targeting efflux pumps to overcome antifungal drug resistance. Fut. Med. Chem. 8, 1485-1501 (2016).

67. Cowen, L. E., Sanglard, D., Howard, S. J., Rogers, P. D. \& Perlin, D. S. Mechanisms of antifungal drug resistance. Cold Spring Harb. Perspect. Med. 5, a019752 (2015).

68. Prasad, R. \& Rawal, M. K. Efflux pump proteins in antifungal resistance. Front. Pharmacol. 5, 202 (2014).

69. Schubert, S. et al. Regulation of efflux pump expression and drug resistance by the transcription factors Mrr1, Upc2, and Cap1 in Candida albicans. Antimicrob. Agents Chemother. 55, 2212-2223 (2011).

70. Vasicek, E. M. et al. Disruption of the transcriptional regulator Cas5 results in enhanced killing of Candida albicans by fluconazole. Antimicrob. Agents Chemother. 58, 6807-6818 (2014).

71. Liu, S. et al. Synergistic effect of fluconazole and calcium channel blockers against resistant Candida albicans. PLoS ONE 11, e0150859 (2016).

72. Hameed, S., Dhamgaye, S., Singh, A., Goswami, S. K. \& Prasad, R. Calcineurin signaling and membrane lipid homeostasis regulates iron mediated multidrug resistance mechanisms in Candida albicans. PLoS ONE 6, e18684 (2011).

73. Sorgo, A. G. et al. Effects of fluconazole on the secretome, the wall proteome, and wall integrity of the clinical fungus Candida albicans. Eukaryot. Cell 10, 1071-1081 (2011)

74. Saarikangas, J. \& Barral, Y. Protein aggregation as a mechanism of adaptive cellular responses. Curr. Genet. 62, 711-724 (2016).

75. Corona, F. \& Martinez, J. L. Phenotypic resistance to antibiotics. Antibiotics2, 237-255 (2013).

76. Arthington-Skaggs, B. A., Warnock, D. W. \& Morrison, C. J. Quantitation of Candida albicans ergosterol content improves the correlation between in vitro antifungal susceptibility test results and in vivo outcome after fluconazole treatment in a murine model of invasive candidiasis. Antimicrob. Agents Chemother. 44, 2081-2085 (2000).

77. Colombo, A. L. et al. Prognostic factors and historical trends in the epidemiology of candidemia in critically ill patients: an analysis of five multicenter studies sequentially conducted over a 9-year period. Intens. Care Med. 40, 1489-1498 (2014).

78. Diezmann, S., Michaut, M., Shapiro, R. S., Bader, G. D. \& Cowen, L. E. Mapping the Hsp90 genetic interaction network in Candida albicans reveals environmental contingency and rewired circuitry. PLoS Genet. 8, e1002562 (2012).

79. Vale-Silva, L. A. et al. Azole resistance by loss of function of the sterol Delta(5),(6)-desaturase gene (ERG3) in Candida albicans does not necessarily decrease virulence. Antimicrob. Agents Chemother. 56, 1960-1968 (2012).

80. Li, D. D. et al. Using Galleria mellonella-Candida albicans infection model to evaluate antifungal agents. Biol. Pharm. Bull. 36, 1482-1487 (2013). 


\section{Acknowledgements}

We thank members of the Berman and Bennett labs for stimulating discussions throughout the work. We are grateful to G. Palmer, M. Lohse, O. Homann, A. Johnson, R. Ben-Ami, T. White, D. Soll, D. McCallum, F. Odds, D. Sanglard, L. Cowen, P.T.

Magee, B. Cormack, P. Magwene, M. Kupiec, W. Fonzi, S. Noble, B.M. Vincent and S. Lindquist for providing strains. We thank P. Lipke, D. Krysan, M. Fridman, R. Ben-Ami, N. Dror, A. Selmecki, A.C. Gerstein, and A. Forche for helpful comments on the manuscript. This work was funded by European Research Council Advanced Award 340087 (RAPLODAPT) to J.B., by Fundação de Amparo a Pesquisa do Estado de São Paulo (FAPESP, Grant 2017/02203-7), Brazil to A.L.C., by National Institutes of Health grant AI081704 to R.J.B. and R21AI139592 to I.V.E., and by a Brazil Initiative Collaborative Grant from the Watson Institute to R.J.B. and I.V.E.

\section{Author contributions}

I.V.E., R.J.B., and J.B. designed the study; A.R., I.V.E., and A.M.D. collected the data; A.R. and I.V.E. analyzed the data; M.B. produced and analyzed the data in Fig. 3a, d; S.Z. performed the experiment in Supplementary Fig. 7g; E.S.S. constructed mutant strains; N.Z. implemented and helped analyze the data in Fig. 2b; A.L.C. provided clinical isolates and clinical input to the paper; and A.R., I.V.E., R.J.B., and J.B. drafted and edited the manuscript.

\section{Additional information}

Supplementary Information accompanies this paper at https://doi.org/10.1038/s41467018-04926-x.

Competing interests: A.L.C. has received educational grants from Pfizer, Gilead Sciences, United Medical (Brazil), MSD, and TEVAS, and a research grant from Astellas and Pfizer. The remaining authors declare no competing interests.
Reprints and permission information is available online at http://npg.nature.com/ reprintsandpermissions/

Publisher's note: Springer Nature remains neutral with regard to jurisdictional claims in published maps and institutional affiliations.

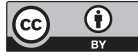

Open Access This article is licensed under a Creative Commons Attribution 4.0 International License, which permits use, sharing, adaptation, distribution and reproduction in any medium or format, as long as you give appropriate credit to the original author(s) and the source, provide a link to the Creative Commons license, and indicate if changes were made. The images or other third party material in this article are included in the article's Creative Commons license, unless indicated otherwise in a credit line to the material. If material is not included in the article's Creative Commons license and your intended use is not permitted by statutory regulation or exceeds the permitted use, you will need to obtain permission directly from the copyright holder. To view a copy of this license, visit http://creativecommons.org/ licenses/by/4.0/.

(C) The Author(s) 2018 